\title{
PERSPECTIVES DE LA LITIGACIÓ PEL CANVI CLIMÀTIC ARRAN DEL CAS URGENDA
}

\section{Perspectives on Climate Litigation after the Urgenda Case}

\author{
ALbert Ruda GonZÁLEZ ${ }^{1}$ \\ Professor agregat de Dret civil \\ Facultat de Dret, Universitat de Girona \\ albert.ruda@udg.edu
}

Recibido: 2 de abril de 2018 / Aceptado: 24 de mayo de 2018

RESUM: La sentència del tribunal de l'Haia de juny de 2016 en el cas Urgenda, que va condemnar l'Estat holandès per no fer prou per combatre el canvi climàtic, va suposar un autèntic terratrèmol per al Dret de la responsabilitat ambiental i va donar lloc a una progènie de reclamacions similars. La seva confirmació pel tribunal d'apel-lació corresponent el passat 9 d'octubre de 2018 sembla donar-hi encara més força. No obstant això, el fet és que aquests pronunciaments judicials susciten qüestions molt profundes no només sobre la responsabilitat (civil o patrimonial de l'Administració, segons el sistema) sinó també d'ordre constitucional. En judicialitzar un tema eminentment polític, permeten de plantejar dubtes sobre si pronunciaments com aquests respecten o no la deguda separació entre els poders de l'Estat. Aquest article analitza críticament unes sentències que, si bé han donat una gran visibilitat a una qüestió de gran urgència i encara d'actualitat, sembla pressuposar que un tribunal és el millor lloc per a jutjar la responsabilitat pel canvi climàtic. Aquest treball s'acaba preguntant si una reclamació "a la Urgenda" seria possible en el nostre sistema i quin seria previsiblement el seu resultat.

\footnotetext{
1 Treball elaborat en el marc del projecte "Modernización y armonización del derecho de daños: fronteras de la responsabilidad, daño resarcible y su valoración (II)", del Ministerio de Economía y Competitividad de España (2016-2019), del qual l'autor és un dels directors. Fou presentat en el I Congrés català de Dret ambiental (Tarragona, gener de 2018).
} 
RESUMEN: La sentencia del tribunal de La Haya de junio de 2016 en el caso Urgenda, que condenó al Estado holandés por no hacer lo suficiente para combatir el cambio climático, supuso un auténtico terremoto para el Derecho de la responsabilidad ambiental y dio lugar a una progenie de reclamaciones similares. Su confirmación por el tribunal de apelación correspondiente el pasado 9 de octubre de 2018 parece darle aun más fuerza. Sin embargo, el hecho es que suscitan cuestiones muy profundas no solo sobre la responsabilidad (civil o patrimonial de la Administración, según el sistema), sino también de orden constitucional. Al haber judicializado un tema eminentemente político, permiten plantear dudas sobre si pronunciamientos como estos respetan o no la debida separación entre los poderes del Estado. El presente artículo analiza críticamente unas sentencias que, si bien han dado una gran visibilidad a una cuestión de enorme urgencia y aún de actualidad, parecen presuponer que un tribunal es el mejor lugar para juzgar la responsabilidad por el cambio climático. Este trabajo se acaba preguntando si una reclamación "a la Urgenda" sería posible en nuestro sistema y cuál sería previsiblemente su resultado.

ABSTRACT: The decision issued by a court in The Hague in June 2016 in the Urgenda case, which sentenced the Dutch State for not doing enough to fight climate change, has been a real earthquake for the law on environmental liability and led to a progeny of similar claims. After being upheld by the appellate court last October $8^{\text {th }}, 2018$, the claim seems to have become even more solid. However, the fact is that it raises very profound issues not only about liability in tort but also of a constitutional nature. Since it has judicialized an eminently political matter, it raises doubts about whether such decisions are fully observant of the proper separation between the powers of the State or not. The present paper critically analyses these decision which, although they have given a high visibility to a matter of great urgency and still a hot topic, seems to presuppose that a court is the best place to judge on the responsibility for climate change. This paper ends up asking whether a claim à la Urgenda would be possible under Spanish law and what its outcome would probably be.

PARAULES CLAU: Responsabilitat ambiental - Canvi climàtic - Urgenda Litigació climàtica - Culpa - Separació de poders. 
PALABRAS CLAVE: Responsabilidad ambiental - Cambio climático Urgenda - Litigación climática - Culpa - Separación de poderes.

KEYWORDS: Environmental liability - Climate change - Urgenda - Climate litigation - Fault - Separation of powers.

SUMARI: I. Introducció. II. El canvi climàtic com a tasca per a la responsabilitat civil. III. La litigació climàtica. 1. La base de les reclamacions. 2. El cas Urgenda. 3. Altres casos. a) El cas Klimaatzaak. b) Els casos Washington Kids i Juliana. c) El cas Leghari. d) El cas de les illes Lofoten. IV. Anàlisi i perspectives de futur. V. Bibliografia.

\section{INTRODUCCIÓ}

Avui en dia hauria de resultar innecessari insistir en com n'és, de preocupant, el canvi climàtic. Els reptes que planteja per a la humanitat són veritablement enormes. Té implicacions tan diverses com profundes, i, com no podia ser d'altra manera, interpel.la també el Dret de la responsabilitat civil o extracontractual, inclosa la comunament ( $\mathrm{i}$ incorrectament) anomenada "responsabilitat patrimonial de l'Administració". ${ }^{2}$

És cert que el debat sobre el canvi climàtic sol centrar-se en termes científics, econòmics o polítics. Tanmateix, hi ha altres enfocaments que són sovint negligits o oblidats però que resulten igualment importants, com són l'ètic o el jurídic. ${ }^{3}$ Tothom coneix que la responsabilitat civil ha tingut com a objecte tradicional els danys a les persones individuals i les seves conseqüències. ${ }^{4} \mathrm{EI}$ cas paradigmàtic que té relació amb el Dret ambiental és el dels danys causats per les immissions o en les relacions de veïnatge. ${ }^{5}$ El veí sorollós, que és un incordi per als que l'envolten, no pot quedar impune, però més enllà del càstig en els casos més greus, està obligat també a reparar els danys que causi. La responsabilitat civil entra en funcionament, doncs, quan algú causa un dany als interessos dels veïns en qüestió. Des d'aquest punt de vista, opera com un

\footnotetext{
2 Vegeu Fernando Pantaleón Prieto, "Los anteojos del civilista: hacia una revisión del régimen de la responsabilidad patrimonial de las Administraciones Públicas", Documentación administrativa, núm. 237-238, 1994, 239-254, p. 239.

${ }^{3}$ Al respecte del primer, vegeu Stephen M. Gardiner / Simon Caney / Dale Jamieson / Henry Shue (eds.), "Prologue" en Climate Ethics. Essential Readings, Oxford University Press. New York, 2010, p. ix.

${ }^{4}$ Es pot veure sobre això Albert Ruda González, El daño ecológico puro, Thomson Aranzadi. Cizur menor, 2007, p. 1 ss.

${ }_{5}^{5}$ Per tots, vegeu Antonio Cabanillas Sánchez, "La responsabilidad civil por inmisiones y daños al medio ambiente", Anuario de Derecho Civil, vol. 49, núm. 1, 1996, 5-74, p. 5 ss.
} 
instrument de tutela d'interessos subjectius de caràcter individual. En aquest pla individual, clàssic o tradicional, hom pot identificar habitualment els dos subjectes que intervenen en la relació obligatòria en la qual s'articula la responsabilitat: d'una banda, el causant del dany (o responsable i, per tant, deutor de la reparació) i, de l'altra, la víctima (part creditora de la dita reparació). Malgrat que sovint es tracti de pertorbacions imponderables, invisibles o no evidents a simple vista, com poden ser les males olors, les vibracions o la radiació elèctrica casos tots ells ben coneguts a la jurisprudència espanyola i d'altres països-el dany tampoc suposa normalment un escull insalvable perquè acabi prosperant la reclamació indemnitzatòria (i àdhuc la de prohibició de conductes similars en el futur). ${ }^{6}$

Les coses canvien bastant, però, quan se salta del nivell individual al col-lectiu, i en lloc de pertorbacions individuals o, diguem-ne, "micro", es passa a danys de tipus plural, social o "macro". És el cas del canvi climàtic. Per començar, el fenomen és encara molt menys evident que les immissions clàssiques. De fet, estem ja acostumats a sentir que es nega la seva existència, i això, fins $i$ tot des de posicions de responsabilitat política o la càtedra. És quelcom que succeeix perquè o bé els danys no són tan aparents, ni es perceben a simple vista, o bé es pot fer veure, segons sembla, que no existeixen. Certament, el dany al clima, consistent en el seu canvi perjudicial o a pitjor, és resultat d'una influència silenciosa, es podria dir, però no per això menys real. ${ }^{7}$

Part de la complexitat dels danys climàtics rau, precisament, en el fet que van més enllà de l'esfera purament subjectiva o individual, i això, en un doble sentit. Primerament, no està gens clara la identitat de la persona causant o responsable. Això pot sembla paradoxal, però en un context en què tots i cadascun de nosaltres contribuïm, velis nolis, amb les nostres decisions quotidianes de consum o d'altre tipus, a agreujar la situació del medi ambient i, de retruc, a empitjorar el canvi climàtic, no resulta gens fàcil individualitzar o singularitzar un

\footnotetext{
6 Vegeu per tots Joan Egea Fernández, "Condiciones medioambientales y derechos fundamentales. Inmisiones perjudiciales que obligan a abandonar el domicilio (a propósito de la Sentencia del TEDH de 9 de diciembre de 1994)", Derecho Privado y Constitución, núm. 9, 1996, p. 323-364, 347.

${ }^{7}$ Al respecte, en un to divulgatiu, es pot veure Roberto Brasero, La influencia silenciosa. Cómo el clima ha condicionado la historia, Espasa. Madrid, 2017, p. 11 ss.
} 
responsable. Estranyament, en un context on tots són (som) responsables, ningú no ho acaba essent.

A aquest respecte, convé recordar que les influències que afecten el clima són innumerables, i que sovint no es poden ni tan sols tenir en compte de manera aïllada. Un petit desplaçament de casa a la feina en vehicle privat, per exemple, resulta negligible si se'l jutja per separat (apart del fet que no hi ha antijuricitat en una conducta així, com tampoc culpa o negligència). És justament l'acumulació de milions de contribucions -individualment irrisòries, però danyoses en el seu conjunt- el que contribueix al problema global del canvi climàtic. Així doncs, una hipotètica reclamació podria semblar, d'entrada, condemnada al fracàs, car seria pràcticament impossible identificar a algú que fos més responsable que els altres - a menys que portéssim tota la societat a judici, quelcom per al qual el Dret de la responsabilitat civil clarament no serveix. $\mathrm{O}$ a menys que canviéssim l'enfocament tradicionalment adoptat en relació amb la causalitat, i ens acontentéssim amb un concepte de causalitat consistent en el mer increment del risc que el dany arribi a produir-se. Aquest pas, que s'ha adoptat tímidament en el context dels danys personals causats per l'exposició a la pols d'amiant, ${ }^{8}$ no ha estat, però, generalitzat, ni resulta pacífic ni clarament generalitzable ni exportable al nostre sistema. ${ }^{9}$

En segon lloc, els problemes no es limiten a la posició activa o del causant o agent del dany, sinó que també s'estenen a la posició passiva o de la víctima. Car, si la contaminació ens afecta a tots, les víctimes seríem també tots plegats. El canvi climàtic és, com s'ha dit amunt, un fenomen col-lectiu, global, i per tant el dany té també necessàriament aquest caràcter. I tanmateix, seria difícil de concretar, per a una persona concreta, en què l'afecta exactament el canvi climàtic. Possiblement, es tracti només d'una qüestió de risc, capaç de ser quantificada de manera estadística, però no en termes absoluts. Per exemple, el canvi climàtic pot determinar que una persona o un col-lectiu pateixi un risc major a la mitjana de patir un càncer de pell, o una malaltia càrdio-respiratòria, etc. Concretament, en relació amb el càncer, s'ha posat de manifest que

${ }^{8}$ Com apunten Myles R. Allen / Richard Lord, "The blame game", Nature núm. 432, 2004, 551 552, p. 552.

${ }^{9}$ Es pot veure al respecte Albert Ruda González, "From Salamander's Wool to Lethal Dust: Asbestos Liability Under Spanish Law in Light of Heneghan", European Review of Private Law, 2017, vol. 25, núm. 6, 1117-1133, p. 1117. 
l'escalfament del planeta i el dany a la capa d'ozó pot provocar un increment en el nombre de casos del càncer de pell. ${ }^{10}$ Però freqüentment serà impossible escatir, en el nivell individual de la víctima concreta, si aquell càncer de pell (o d'altre tipus) o aquella altra malaltia específics es deuen al canvi climàtic o a una altra causa. ${ }^{11}$ Apart del fet que molts danys seran massa minúsculs o trivials per a ser presos en consideració: cal pensar, per exemple, en una mica de tos o una al-lèrgia - tal vegada, de també difícil atribució causal. Així doncs, si tots estan sotmesos a un major risc, però aquest és difícilment quantificable, i en tot cas quan el dany es materialitza és o molt petit o impossible de traçar amb una causa concreta, el més racional és que les "víctimes" simplement s'abstinguin de reclamar. L'anomenada "apatia racional" és el resultat normal d'aquest estat de coses. $^{12}$

El que és pitjor, si resulta que els mateixos que causen el dany amb les seves innumerables contribucions (llegeixi's, contaminació) són els que l'acaben patint, ens enfrontem a un cercle viciós, difícil de trencar amb l'expedient tècnic de la responsabilitat civil. Si el creditor-víctima coincideix amb el deutor-responsable, ens trobem, segons l'esquema clàssic, davant d'un supòsit de confusió de deute, en què l'efecte és inevitablement l'extinció del mateix (art. 1192 I del Codi civil espanyol).

El pessimisme o derrotisme al qual semblen emmenar les consideracions anteriors, però, ha donat un tomb inesperat, almenys a Europa, a partir d'una primera sentència dictada per un tribunal holandès, recentment confirmada pel tribunal d'apel-lació corresponent. Com tothom coneix, el Dret holandès —reflex inevitable de la seva societat- s'ha caracteritzat per la seva posició heterodoxa en molts aspectes, com ara l'eutanàsia o el tràfic de drogues. Doncs bé, els holandesos han fet també una contribució essencial a nivell planetari en matèria de la responsabilitat climàtica, com és resoldre el problema abans descrit en el sentit de fer respondre l'Estat. Tot i que no és el primer cas del que, en un sentit

\footnotetext{
10 Vegeu AK Bharath / RJ Turner, "Impact of climate change on skin cancer", Journal of the Royal Society of Medicine, vol. 102, núm. 1, 2009, 215-218, p. 218.

${ }^{11}$ Massa sovint, només se'n pot indicar una probabilitat força petita. Vegeu al respecte Troyen A. Brennan / Robert F. Carter, "Legal and Scientific Probability of Causation of Cancer and Other Environmental Disease in Individuals", Journal of Health Politics, Policy and Law, vol. 10, núm. $1,1985,33-80$, p. 33 i ss.

12 Vegeu Hans Christian Bugge, "Twelve fundamental challenges in environmental law", en Christina Voigt (ed.), Rule of Law for Nature. New Dimensions and Ideas in Environmental Law, Cambridge University Press, Cambridge, 2003, 3-26, p. 13.
} 
ampli, es pot denominar "litigació climàtica", sí que és possiblement el més comentat i el que, de moment, sembla estar tenint una major influència a la pràctica en altres països. ${ }^{13}$

El present article estudia i contextualitza aquest cas des d'una perspectiva crítica. Per a algú que és un ferm defensor de la natura i el medi ambient, qualsevol notícia en el sentit de contribuir a fer que els responsables de la destrucció d'aquells siguin condemnats a pagar pels seus fets semblaria, a primera vista, una notícia excel-lent. I tanmateix, les coses no són ni de bon tros tan positives ni tan senzilles com semblen. No només perquè la sentència del tribunal d'apel-lació que confirma la d'instància podria ser novament recorreguda i acabar en no res, sinó també perquè sembla dubtós que pugui servir de patró o model per a reclamacions anàlogues en tots els països sense cap mena de dubte. En aquest sentit, un cas noruec recent dona un avís per a navegants que no convé ignorar, especialment si es pensa, com sembla que es pensa, en interposar una reclamació d'aquest tipus davant dels tribunals espanyols.

\section{EL CANVI CLIMÀTIC COM A TASCA PER A LA RESPONSABILITAT CIVIL}

El canvi climàtic planteja reptes molt seriosos per al Dret perquè les seves implicacions són múltiples, com ja s'ha dit. Per començar, la víctima des del punt de vista dels danys és el medi ambient com a tal. El dany al canvi climàtic afecta un recurs col-lectiu o de tots: el clima. És un dany col-lectiu o no individual, que no encaixa bé en el plantejament o estructura individualista del Dret de la responsabilitat civil. En fi, la víctima del dany al clima no és una persona concreta, sinó el medi ambient en si mateix, l'ambient per se. Es tracta d'un dany ecològic pur: ecològic perquè afecta el medi ambient, i pur perquè no pressuposa un dany a un interès individual. Això és així perquè el Dret no reconeix personalitat al medi ambient com a tal, sinó només a les persones — per bé que dispensi als animals certa protecció especial.

Aquest plantejament antropocèntric té profundes arrels culturals i es manté com a predominant als diversos ordenaments, malgrat ser impugnat darrerament. En

13 Rechtbank (Rb.) Den Haag 24 juni 2015, ECLI: NL:RBDHA :2015:7145 $<$ https://uitspraken.rechtspraak.nl/inziendocument?id=ECLI:NL:RBDHA:2015:7145>. Per a la traducció a l'anglès vegeu: <https://elaw.org/system/files/urgenda_0.pdf>. 
efecte, cada cop sembla que hi ha més veus en favor d'una "natura humanitzada" que obligui a replantejar els termes de la relació persona humana-ambient. ${ }^{14}$ Això planteja un primer problema, ja que la responsabilitat civil està mal equipada inicialment per a respondre als problemes col-lectius. L'enfocament clàssic de la responsabilitat individual es troba en dificultats quan el que està en joc no és un interès d'una persona concreta sinó un interès col-lectiu, com la protecció ambiental. És cert que de vegades és possible particularitzar danys concrets relacionats amb el canvi climàtic. Per exemple, es pot dir que un cert nombre de morts són produïdes per l'increment exagerat de les temperatures durant alguns estius (com el de 2003), resultat del ja referit canvi climàtic. ${ }^{15} \mathrm{Amb}$ tot, com s'ha dit, resulta dubtós que hi hagi un nexe causal clar en el sentit requerit pel Dret de la responsabilitat civil.

A l'anterior cal afegir una altra circumstància. El canvi climàtic és una consequència del desenvolupament industrial que, com tothom coneix, ha tingut lloc principalment en certs països. Així doncs, té un vessant no individual, sinó internacional. La qüestió que cal posar llavors a sobre de la taula és la de la responsabilitat dels Estats entre si, responsabilitat que es planteja per la conducta dels Estats mateixos o de subjectes que es troben o desenvolupen la seva activitat en el territori d'aquests —qüestió aquesta darrera que es deixa de banda en aquest treball.

En la mesura que el canvi climàtic afecta pràcticament totes les esferes de la nostra vida com a persones, pot dir-se sense por a equivocar-se que és el principal problema del nostre temps. En efecte, està ja obligant a poblacions senceres a desplaçar-se, amb tot el que una migració comporta no només per als que es desplacen, sinó també per als que acullen. Com s'ha posat en evidència recentment amb el cas de la guerra de Síria, els desplaçats pateixen conseqüències molt dures i la seva reallotjament no és gens senzill, com la problemàtica actual sobre la immigració a Europa posa en relleu.

L'anterior connecta amb un altre repte, ja que el canvi climàtic tindrà un impacte enorme sobre els drets humans. Els interessos més preuats d'una persona,

\footnotetext{
${ }^{14}$ Vegeu en aquesta línea Eudald Carbonell, Elogio del futuro. Manifiesto por una conciencia crítica de especie, Arpa. Barcelona, 2018, p. 91. Semblantment, a favor de reconèixer un estatus superior al medi ambient, vegeu Thomas Berry, The Great Work, Three Rivers Press. New York, 1999, p. 161.

${ }^{15}$ Vegeu Allen / Lord, “The blame game”, cit., p. 552
} 
protegits jurídicament mitjançant l'expedient tècnic d'aquests drets, es veuen posats en perill d'una manera preocupant. En suma, el canvi climàtic crea violacions dels drets humans. ${ }^{16}$ En aquest sentit, el nombre de persones afectades pel canvi climàtic previsiblement excedirà en molt el total de víctimes de les pitjors violacions de drets humans que tenen lloc actualment o hagin ocorregut en el passat. ${ }^{17}$

En el fons, doncs, la problemàtica del canvi climàtic constitueix una qüestió de protecció de drets humans. ${ }^{18}$ La perspectiva dels drets humans ajuda a assenyalar la connexió del medi ambient l'impacte que el deteriorament d'aquest últim té sobre la vida, la salut, la vida privada , o la propietat. ${ }^{19}$ És també en clau de drets humans que s'insisteix en la injustícia dels intercanvis econòmics entre el nord i el sud globals. ${ }^{20}$ En aquest sentit, el canvi climàtic planteja qüestions profundes sobre justícia (la "justícia climàtica", com ara se l'anomena), a les quals tradicionalment no s'ha prestat atenció. ${ }^{21} \mathrm{Hi}$ ha fins i tot qui es planteja que és un dret humà el de contaminar o participar en el comerç de drets d'emissió, cosa que altres neguen. ${ }^{22}$ Així doncs, la política que s'adopti en relació amb el canvi climàtic (inclosa la política en matèria de la responsabilitat civil) ha de tenir en compte també la protecció dels drets humans. ${ }^{23}$ En suma, s'està parlant de responsabilitat sobre la vulneració de drets humans en relació amb el canvi climàtic.

\footnotetext{
${ }^{16}$ Vegeu Mary Robinson, "Foreword", en Stephen Humphreys (ed.), Human Rights and Climate Change, Cambrigde University Press. Cambridge, 2010, xvii-xx, p. xviii.

17 Vegeu Jaap Spier, Shaping the law for global crises: thoughts about the role the law could play to come to grips with the major challenges of our time, Eleven International Publishing. The Hague, 2012, p. 5.

18 Novament, vegeu Spier, Shaping the law ..., cit., p. 45 i 82.

${ }^{19}$ Vegeu Alan Boyle, "Human Rights and the Environment: Where Next?", European Journal of International Law, 2012, vol. 23, núm. 3, 613-642, p. 613.

20 Vegeu J. Timmons Roberts / Bradley C. Parks, "Ecologically Unequal Exchange, Ecological Debt, and Climate Justice. The History and Implications of Three Related Ideas for a New Social Movement", International Journal of Comparative Sociology, 2009, vol. 50, núm. 3-4, 385-409, p. 386.

${ }^{21}$ Vegeu Jutta Brunnée, "Climate Change, global environmental justice and international environmental law" en Jonas Ebbeson / Phoebe Okowa (eds), Environmental Law and Justice in Context, Cambridge University Press, Cambridge, 2009, 316-331, p. 318.

22 Vegeu al respecte Tim Hayward, "Human Rights Versus Emissions Rights: Climate Justice and the Equitable Distribution of Ecological Space”, Ethics \& International Affairs, 2007, vol. 21, núm. 4, 431-450, p. 440 ss.

${ }^{23}$ Com bé apunten Sheila R. Foster / Paolo Galizzi, "Human rights and climate change: building synergies for a common future", en Daniel A. Farber / Marjan Peters (ed.), Climate Change Law. Elgar Encyclopedia of Environmental Law, Elgar. Cheltenham, 2016, 43-63, p. 43.
} 
Així doncs, es pot assenyalar que el canvi climàtic és "el" repte, no només per a la societat en general, sinó per al Dret en particular. Com va manifestar el secretari general de Nacions Unides, Ban Ki-moon, en la cerimònia d'obertura de la cimera sobre el canvi climàtic a Abu Dhabi el 4 de maig de 2014: "El canvi climàtic és la qüestió definidora del nostre temps. Si no actuem de manera urgent, tots els nostres plans per a una major prosperitat i seguretat globals se n'aniran en orris". ${ }^{24}$

Un ressò d'aquesta afirmació es troba en els qui diuen que el canvi climàtic és, de fet, el major repte al que s'hagi enfrontat mai la humanitat. ${ }^{25}$ Especialment, per a les empreses suposarà un desafiament formidable, per al qual la gran majoria, malauradament, no està preparada. ${ }^{26}$ Resulta indispensable que comencin a adoptar les seves polítiques a les necessitats d'aquesta lluita. ${ }^{27}$

Per descomptat, no pot donar-se l'esquena al fet que el canvi climàtic és encara negat per alguns. Existeix, especialment en els últims anys, una major insistència en què el canvi climàtic és simplement una mentida, com existeix, també, una tendència a minimitzar-ne els possibles efectes. Alguns polítics, tant a Espanya com als Estats Units d'Amèrica, han assumit una posició negacionista, sigui per pura ignorància, per irresponsabilitat, o per una altra raó. Sense anar molt lluny, a Espanya varen ser molt comentades les declaracions del president M. Rajoy, en què treia ferro a l'assumpte basant-se en l'opinió d'un familiar seu. ${ }^{28} \mathrm{En}$ efecte, bona part del problema del canvi climàtic es produeix per la nostra manca de coneixement de com funciona l'ecologia. ${ }^{29}$ Apart de certa desconnexió entre els discursos filosòfic-ambientals i el discurs polític. ${ }^{30}$

${ }^{24}$ Climate change is the defining issue of our time. If we do not take urgent action, all our plans for increased global prosperity and security will be undone. Vegeu $<$ http://www.un.org/apps/news/story.asp?NewsID=28458> [Darrera consulta, 16 de desembre de 2018].

${ }^{25}$ Vegeu Spier, Shaping the law..., cit., p. 11.

${ }^{26}$ Vegeu Elbert R. de Jong / Jaap Spier, "Climate Change: A Major Challenge and a Serious Threat to Enterprises", en Dovenschmidt Quaterly, núm . 1, 2013, 36-43, p. 36.

27 Vegeu Expert Group on Climate Obligations of Enterprises, Principles on Climate Obligations of Enterprises, Eleven International Publishing. The Hague, 2018, p. 1 ss.

${ }^{28}$ Vegeu Cadena Ser, "Rajoy resta importancia al cambio climático aludiendo a su primo científico", <http://cadenaser.com/ser/2007/10/22/espana/1193010614_850215.html> [Darrera consulta, 16 de desembre de 2018].

${ }^{29}$ Vegeu Aldo Leopold, Una ética de la tierra, Catarata. Madrid, 2017 (2ª edición) p. 202.

30 Vegeu Avner De-Shalit, The Environment Between Theory and Practice, Oxford University Press. Oxford, 2004, p. 8. 
No obstant això, no pot donar-se l'esquena a l'aspecte ideològic. Concretament, la lluita contra el canvi climàtic requereix una intervenció de l'Estat de tal calibre que desperta la ira dels partidaris del neoliberalisme imperant. ${ }^{31}$ En efecte, la discussió sobre el canvi climàtic traspua una profunda discrepància de caràcter ideològic. ${ }^{32}$ En tot cas, el fet és que, per al Dret, el canvi climàtic és una realitat que ve donada des de fora. Així doncs, no és el Dret el que decideix si hi ha canvi climàtic, sinó que aquest resulta d'una constatació científica, d'un estat de coses en el coneixement humà. El canvi climàtic existeix perquè així ho diu el consens científic, l'estat de la ciència és precisament aquest. Per això, en el Dret no es pot qüestionar que hi hagi o no canvi climàtic, sinó que cal preguntar-se per les seves implicacions.

En aquest sentit, sembla que el consens científic mundial queda recollit ara per ara per l'anomenat Intergovernmental Panel on Climate Change (IPCC), ${ }^{33}$ I'organisme científic auspiciat per Nacions Unides, el qual aspira a expressar un parer el més objectiu possible sobre el canvi climàtic. L'IPPC es va crear (el 1988, per més senyes) precisament per avaluar les proves d'un canvi climàtic provocat per l'home, així com per determinar el seu impacte i la nostra vulnerabilitat i perquè es pronunciés científicament sobre com adaptar-s'hi i mitigar-ne els efectes. ${ }^{34}$ És, doncs, un organisme científic en el si de Nacions Unides cridat a establir quin és l'state of the art del coneixement científic sobre el canvi climàtic. El punt de vista de l'esmentat Panell té un valor especial, no només per aglutinar i destil-lar els estudis que es realitzen sobre aquesta matèria sinó perquè funciona com si es tractés d'una espècie de tribunal, en què els punts de vista se sotmeten a examen d'una manera semblant a un procés judicial regit pel principi de contradicció. Els seus informes tenen per això aquest valor especial, molt superior al que pugui tenir un simple article de revista, per exemple. És, de fet, la veu més autoritzada des del punt de vista científic i tècnic pel que fa a canvi

\footnotetext{
${ }^{31}$ Com argumenta Naomi Klein, This Changes Everything, Penguin. London, 2014, p. 44 ss.

32 Vegeu Manuel Arias Maldonado, "La ideología del clima", Revista de Libros, 10.1.2018 $<$ https://www.revistadelibros.com/articulo_imprimible.php?art=1709\&t=blogs> [Darrera consulta, 16 de desembre de 2018].

${ }^{33}$ La pàgina web del qual es troba a <http://www.ipcc.ch/> [Darrera consulta, 16 de desembre de 2018].

${ }^{34}$ Vegeu Duncan French / Benjamin Pontin, "The science of climate change: a legal perspective on the IPCC", en Daniel A. Farber / Marjan Peters (ed.), Climate Change Law. Elgar Encyclopedia of Environmental Law, Elgar. Cheltenham, 2016, 9-19, p. 9.
} 
climàtic es refereix. ${ }^{35}$ En particular, el Panell intenta abstenir-se de posicionar-se políticament i així preservar la seva independència i objectivitat. ${ }^{36}$ Doncs bé, el cas és que I'IPPC conclou que: 1) el canvi climàtic ja està tenint lloc, i 2) l'únic que cal saber és quan, on i com se'n manifestaran els efectes.

En efecte, en un informe encarregat pel Ministeri britànic d'afers exteriors, que es va publicar el 2005, diversos experts van assenyalar que el canvi climàtic és una causa potencial d'inestabilitat social i política, i per tant de greus conflictes, a causa de l'escassetat de l'aigua, i la migració de grans grups de persones motivades per catàstrofes humanes (o humanitàries, com se sol dir també, tot $\mathrm{i}$ potser menys correctament). En aquest sentit, s'assenyala que el canvi climàtic posa en relleu la interrelació entre les societats, els llocs i el medi ambient a l'escala geogràfica i política. ${ }^{37}$ I que és possiblement la causa del conflicte social i polític a Síria, que està tenint lloc actualment, ${ }^{38}$ i per tant de la crisi migratòria actual a Europa, ${ }^{39}$ si bé aquest punt de vista no és admès per tothom. ${ }^{40}$ És probable que el fenomen sigui més complex i tingui una arrel multicausal però en tot cas interessa subratllar la importància causal del canvi climàtic encara que sigui junt amb altres factors.

Així doncs, pot partir-se de la base que el canvi climàtic ja està passant i produint efectes perjudicials. Els escèptics en matèria de canvi climàtic s'han quedat simplement sense arguments. ${ }^{41}$ Fins $i$ tot hi ha estimacions sobre el nombre de morts que el canvi climàtic causa cada any, concretament unes 300.000. ${ }^{42}$ Aquesta afirmació no desvirtua el que s'ha dit més amunt sobre les dificultats d'establir un nexe causal entre la contaminació i el dany, ja que es tracta d'una estimació i possiblement sigui possible donar els números globals, però no dir en

\footnotetext{
${ }^{35}$ Vegeu Mark Maslin, Climate Change. A Very Short Introduction, Oxford University Press. Oxford, 2014 (3rd edition), p. 10.

${ }^{36}$ Vegeu novament French / Pontin, "The science of climate change..." cit., p. 11.

37 Vegeu Richard Aspinall, "Geographical Perspectives on Climate Change", Annals of the Association of American Geographers, vol. 100, núm. 4, 2010, 715-718, p. 715.

38 Vegeu David King / Daniel Schrag / Zhou Dadi / Qi Ye / Arunabha Ghosh, Climate Change. A Risk Assessment, 2015 <http://www.csap.cam.ac.uk/projects/climate-change-risk-assessment/> [Darrera consulta, 31 de març de 2018].

39 Vegeu Justin Worland, "How Climate Change Could Make the Migrant Crisis Worse", Time, 2017 <http://time.com/5076003/climate-change-migration-trump/> [Darrera consulta: 16 de desembre de 2018].

40 Vegeu Jan Selby / Omar S. Dahi / Christiane Fröhlich / Mike Hulmee, "Climate change and the Syrian civil war revisited", Political Geography, 2017, vol. 60, 232-244, p. 232 ss.

${ }^{41}$ Semblantment, vegeu Alan Wells, "Climate Change: The Final Countdown", European Environmental Law Review, núm. 3, 2007, 62-65, p. 65.

42 Per a més dades es pot veure Spier, Shaping the law ..., cit., p. 18.
} 
un cas concret que la mort de la persona es deu al canvi climàtic. En tot cas l'estimació planteja un problema inajornable, que constitueix un dilema moral enorme ${ }^{43}$ així com també un repte gegantí per al Dret, i això inclou, també, el de la responsabilitat civil, com de seguida es veurà.

En fi, la definició de canvi climàtic està prevista per un instrument internacional, com és la Convenció Marc de les Nacions Unides sobre el Canvi Climàtic (CMNUCC), ${ }^{44}$ de 1992 (en vigor des de 1994). Segons que preveu, el canvi climàtic és a change of climate which is attributed directly or indirectly to human activity that alters the composition of the atmosphere and which is in addition to natural climate variability observed over comparable time periods (art. 7.2). La definició posa l'accent en l'origen humà o antròpic del canvi climàtic, en l'afectació de l'atmosfera, i al fet que el canvi és més gran que el degut a la mera variabilitat natural.

\section{LA LITIGACIÓ CLIMÀTICA}

\section{La base de les reclamacions}

Com ja s'ha posat en relleu més amunt, són ja diverses les reclamacions judicials que s'han interposat per sol-licitar una declaració de responsabilitat pel canvi climàtic. De manera no exhaustiva, cal referir-se almenys als següents països: Holanda (cas Urgenda), EUA (casos Washington Kids i Juliana), Bèlgica (cas Klimaatzaak), el Pakistan (cas Leghari), el cas KlimaSeniorinnen (Suïssa), i es podria fer esment a altres casos a Nova Zelanda, Suècia i Noruega, etc. No és casual que hi hagi autors que hagin assenyalat que hi ha raons per pensar que la litigació climàtica serà una indústria en auge. ${ }^{45}$

Hom es podria preguntar tal vegada per quin motiu aquestes reclamacions s'estan plantejant precisament en el moment present. Hi ha diverses raons que ho expliquen. Principalment, els textos internacionals, siguin de caràcter normatiu o no, han anat evolucionant cap a un major reconeixement del canvi climàtic i de la problemàtica que aquest suscita. En aquest sentit, cal citar

\footnotetext{
${ }^{43}$ Sobre el qual es pot veure Antxon Olabe Egaña, Crisis climática-ambiental. La hora de la responsabilidad, Galaxia Gutenberg. Barcelona, 2016, p. 17 ss.

44 United Nations Framework Convention on Climate Change (UNFCC), $<$ http://unfccc.int/portal_espanol/informacion_basica/la_convencion/items/6196.php> [Darrera consulta, 16 de desembre de 2018].

45 Vegeu Spier, Shaping the law..., cit., p. 88.
} 
I'Universal Covenant affirming a human right to commons - and rights-based governance of Earth 's natural resources (Commons' Law Project, 2013);46 una declaració de l'Associació Internacional de Dret (International Law Association) ${ }^{47}$ sobre els principis jurídics relatius al canvi climàtic (Declaration of Legal Principles Relating to Climate Change, 2014);48 un esborrany de llei model sobre els remeis jurídics per al canvi climàtic (Model Statute on Legal Remedies for Climate Change [draft]), elaborat per un grup de treball de la International Bar Association el 2014) ${ }^{49} \mathrm{o}$ els Principis d'Oslo sobre les obligacions globals del canvi climàtic (Oslo Principles on Global Climate Change obligations) ${ }^{50}$ elaborats per un grup de professors encapçalats per Jaap Spier, catedràtic de Dret civil i advocat general del Tribunal Suprem (Hoge Raad) holandès (2015).

Aquestes reclamacions tenen en comú diversos aspectes. Es tracta en primer lloc de reclamacions interposades per Organitzacions No Governamentals (NGO) o ciutadans del carrer, o una combinació de tots dos. Des del punt de vista dels demandats, sol tractar-se de l'Estat o d'una agència o organisme governamental. L'objecte de la reclamació consisteix en exigir una conducta més rigorosa des del punt de vista ambiental, concretament, en relació amb el nivell d'emissions de gasos d'efecte hivernacle (GHG, greenhouse gas). Més concretament, es tracta d'exigir a l'Estat que compleixi amb allò que ell mateix s'ha obligat a fer, com passa en el cas Urgenda, a qual de seguida es farà referència.

Pel que fa a la metodologia, les reclamacions tenen una sòlida fonamentació científica, de manera que citen nombrosos estudis d'investigació en revistes especialitzades o informes com els del Panell abans referit. Abunden per això les referències a publicacions $\mathrm{i}$ informes científics nacionals $\mathrm{o}$ internacionals. Pel que

\footnotetext{
46 <http://commonslawproject.org/sites/default/files/clp_universal_covenant.pdf> [Darrera consulta, 16 de desembre 2018].

${ }^{47}<$ http://www.ila-hq.org/> [Darrera consulta, 16 de desembre de 2018]. 48

<https://ila.vettoreweb.com/Storage/Download.aspx?DbStorageld=1253\&StorageFileGuid=f93d 2f56-5629-40aa-a940-34c7da6e8545> [Darrera consulta, 16 de desembre de 2018].

$49<$ https://www.ibanet.org/> [Darrera consulta, 16 de desembre de 2018]. En particular, cal veure'n l'informe "Achieving Justice and Human Rights in an Era of Climate Disruption. International Bar Association Climate Change Justice and Human Rights Task Force Report", IBA, 2014, <https://www.ibanet.org/Document/Default.aspx?DocumentUid=0f8cee12-ee564452-bf43-cfcab196cc04> [Darrera consulta, 31 de març de 2018].

$50<$ <ttps://globaljustice.yale.edu/oslo-principles-global-climate-change-obligations> [Darrera consulta, 16 de desembre de 2018].
} 
fa a la fonamentació normativa, es basen en el Dret europeu, el Dret intern o nacional del país corresponent, i en textos internacionals de drets humans (com la Convenció Europea de Drets Humans [CEDH]). ${ }^{51}$

Pel que fa als textos que serveixen de base de la demanda, cal referir-se a la ja citada Convenció Marc de les Nacions Unides sobre el Canvi Climàtic; els Acords de Cancún (2011);52 l'Esmena de Doha al Protocol de Kyoto (2012);53 a tot això cal afegir la jurisprudència del Tribunal Europeu de Drets Humans (Estrasburg), ${ }^{54}$ concretament la relativa a la protecció del medi ambient. Convé aclarir que la Convenció Europea abans esmentada no protegeix directament el dret al medi ambient, però indirectament sí que queda protegit per la tutela de la intimitat en l'àmbit domiciliar (art. 8.2 CEDH). També són habituals les referències a la jurisprudència del Tribunal Internacional de Justícia (La Haia), en concret als principis de no fer mal (no harm), precaució (Precautionary principle), equitat (equity principle) i desenvolupament sostenible (sustainable development). Aquest darrer en particular és un concepte fonamental, que tant el Dret públic com el privat han d'analitzar encara en bona mesura com els afecta. ${ }^{55}$

D'entre aquests principis, interessa especialment el principi de precaució. Com és sabut, està reconegut per la Declaració de Rio de Janeiro (1992), ${ }^{56}$ concretament en el seu principi 15. Diu així:

Per tal de protegir el medi ambient, els Estats hauran d'aplicar àmpliament el criteri de precaució conforme a les seves capacitats. Quan hi hagi perill de dany greu o irreversible, la manca de certesa científica absoluta no s'ha d'utilitzar com a raó per postergar l'adopció de mesures eficaces en funció dels costos per impedir la degradació del medi ambient.

\footnotetext{
51 <http://www.echr.coe.int/Documents/Convention_SPA.pdf> [Darrera consulta, 16 de desembre de 2018]. 52

$<$ http://unfccc.int/portal_espanol/informacion_basica/la_convencion/conferencias/cancun/items/ 6212.php> [Darrera consulta, 31 de març de 2018].

$53<$ <https://unfccc.int/files/kyoto_protocol/application/pdf/kp_doha_amendment_spanish.pdf> [Darrera consulta, 16 de desembre de 2018].

54 Per als textos complets de les sentències, en anglès 0 francès, vegeu: $<$ https://hudoc.echr.coe.int/eng > [Darrera consulta, 16 de desembre de 2018].

55 Vegeu al respecte Jeffrey D. Sachs, La era del desarrollo sostenible, Ediciones Deusto. Barcelona, 2015, p. 16 ss., amb més referències.

56 Es pot veure a <http://www.un.org/spanish/esa/sustdev/agenda21/riodeclaration.htm> [Darrera consulta, 31 de març de 2018].
} 
El principi de precaució constitueix la base de la majoria de reclamacions. Concretament, és considerat pels Oslo Principles (abans referits) com la base de totes les obligacions que aquests principis imposen als Estats. Segons els mateixos Principis, el principi de precaució obliga els Estats: a) a fer tot el que puguin per mitigar els efectes del canvi climàtic, i b) a començar el més aviat possible. Aquest criteri és coherent amb l'opinió d'un dels redactors d'aquests principis, per a qui el principi de precaució té una importància fonamental en aquesta matèria i és el gran oblidat dels llibres sobre Dret de la responsabilitat civil. ${ }^{57}$ Les implicacions del principi de precaució per a la responsabilitat civil només s'han començat a explorar molt recentment. ${ }^{58}$

Deixant això al marge, en aquest punt l'enfocament d'aquests Principis és una mica diferent de la sentència Urgenda, a la qual es farà referència més endavant, ja que per al tribunal holandès del que emana la dita sentència, l'Estat ha de complir el seu compromís de reducció en l'emissió de gasos i ja està. En canvi, els redactors dels Oslo Principles sostenen que ha de fer-se el màxim possible per evitar el canvi climàtic. Així es desprèn de la jurisprudència del TEDH sobre violacions de drets humans. ${ }^{59}$ Això és així almenys per als països desenvolupats, que són els que hi han contribuït. ${ }^{60} \mathrm{En}$ qualsevol cas, convé advertir que el principi de precaució no té encara una acceptació universal, i que no constitueix part del costum internacional, per la qual cosa és dubtós que justifiqui, per si sol, una reclamació d'un particular contra un Estat per la seva responsabilitat climàtica. ${ }^{61}$

El principi d'equitat és també molt important en aquest context, ja que l'equitat obliga, a aquest respecte, a tenir en compte no només les generacions presents, sinó també a les futures (el que se sol anomenar "solidaritat intergeneracional"). Si bé aquest argument és enormement problemàtic, ni que sigui pel fet que

\footnotetext{
${ }^{57}$ Semblantment, Spier, Shaping the law..., cit., p. 63.

58 Vegeu al respecte Elbert de Jong, Voorzorgverplichtingen . Over aansprakelijkheidsrechtelijke normstelling voor onzekere risico's, Proefschrift, Boom juridisch. Den Haag, 2016, p. 67 ss.

59 Vegeu Spier, Shaping the law..., cit., p. 114.

60 Novament, vegeu Spier, Shaping the law..., cit., p. 136.

${ }^{61}$ En aquest sentit, vegeu Matthew Hall, "State Responsibility for the Adverse Impacts of Climate Change on Individuals: Assessing the Potential for an Interdisciplinary Approach", en Stephen Farrall / Tawhida Ahmed / Duncan French (eds.), Criminological and Legal Consequences of Climate Change, Hart. Oxford and Portland Oregon, 2012, 215-240, p. 226.
} 
difícilment es poden tenir obligacions respecte de generacions que simplement no existeixen. ${ }^{62}$

Als anteriors principis cal afegir el de responsabilitats comunes però diferenciades (common but differentiated responsibilities), reconegut per la Declaració de Rio (Principi núm. 7). Segons que disposa, els països industrialitzats tenen un deure més gran, per la seva major capacitat i per la seva responsabilitat històrica, de lluitar contra el canvi climàtic. L'argument té un cert atractiu a primera vista, però novament està plagat de dificultats. El caràcter tan general de la regla impedeix de trobar-hi termes concrets en què realment es pugui plasmar el suposat deure dels països històricament més contaminants respecte dels demés. ${ }^{63}$ En qualsevol cas no hi ha, en canvi, una causa d'exoneració basada en l'argument de minimis, conforme al qual els estats que menys contaminen no són responsables. No cal, doncs, argumentar que la contribució d'un país és merament marginal (i així ho entén la sentència Urgenda).

Un altre puntal sobre el qual es basen les reclamacions són els drets humans. Els drets reconeguts per la Convenció Europea de Drets Humans que es podrien veure afectats pel canvi climàtic són: el dret a la vida, el dret a la intimitat (privacy) i a la privacitat en l'àmbit familiar, el dret a la salut, el dret a l'aigua, dret a l'alimentació, i el dret a la propietat. Hi ha dubtes sobre si també es podria veure afectat el dret a l'autodeterminació dels pobles. Els pobles es veuen afectats si no poden desenvolupar-se en el territori que ocupen i han de abandonar-lo. Així està succeint en el cas de l'illa de Kiribati, al Pacífic. A aquest respecte, la jurisprudència del Tribunal Europeu de Drets Humans sembla anar en la direcció de reconèixer els drets de les víctimes de danys ambientals quan la conducta dels Estats posa en perill el dret d'aquestes a una vida saludable i l'ús de la seva propietat privada. ${ }^{64}$

62 Sobre aquest i altres esculls, vegeu Axel Gosseries / Lukas H. Meyer, "Introduction Intergenerational Justice and Its Challenges", en Axel Gosseries / Lukas H. Meyer, Intergenerational justice, Oxford University Press. Oxford, 2010, 1-21, p. 3 ss.

63 Vegeu al respecte Wilfred Beckerman / Joanna Pasek, Justice, Posterity and the Environment, Oxford University Press. Oxford, 2004, p. 192.

64 Vegeu Hall, "State Responsibility...", cit., p. 236. 
Pel que fa al Dret de la Unió Europea, cal fer referència especialment al Tractat de Funcionament de la Unió Europea (TFUE), ${ }^{65}$ en concret el seu art. 191 (del qual interessen ara els dos primers apartats):

1. La política de la Unió en l'àmbit del medi ambient contribuirà a assolir els següents objectius:

- la conservació, la protecció i la millora de la qualitat del medi ambient,

- la protecció de la salut de les persones,

- la utilització prudent i racional dels recursos naturals,

- el foment de mesures a escala internacional destinades a fer front als problemes regionals o mundials del medi ambient. i en particular a lluitar contra el canvi climàtic.

2. La política de la Unió en l'àmbit del medi ambient tindrà com a objectiu assolir un nivell de protecció elevat, tenint present la diversitat de situacions existents en les diferents regions de la Unió. Es basarà en els principis de cautela i d'acció preventiva, en el principi de correcció dels atemptats al medi ambient, preferentment a la font mateixa, i en el principi de qui contamina paga.

\section{El cas Urgenda}

El cas estrella i que realment ha marcat època fins avui ha tingut lloc a Holanda. Es tracta d'una reclamació interposada per la Fundació Urgenda i 886 ciutadans holandesos. La reclamació ha triomfat en primera instància, en haver estat estimada per un tribunal de districte de l'Haia (Rechtsbank Den Haag) -que no s'ha de confondre amb el Tribunal Internacional de Justícia, situat a la mateixa ciutat-amb data 24 de juny de 2015. Al principi va semblar que l'Estat holandès no anava a recórrer la sentència, però finalment va interposar-hi recurs, resolt novament en sentit favorable per a Urgenda el passat 9 d'octubre de 2018. El tribunal d'apel-lació de l'Haia (Gerechtshof Den Haag) ha rebutjat tots i cadascun dels arguments esgrimits per l'Estat holandès. ${ }^{66}$ No cal dir que l'organització

\footnotetext{
65 Vegeu <http://eur-lex.europa.eu/legal-content/ES/TXT/?uri=CELEX:12012E/TXT> [Darrera consulta, 16 de desembre de 2018].

${ }^{66}$ Gerechtshof Den Haag, 9 October 2018, Zaaknummer 200.178.245/01 (English translation), $<$ https://uitspraken.rechtspraak.nl/inziendocument?id=ECLI:NL:GHDHA:2018:2610> [Darrera consulta, 16 de desembre de 2018].
} 
ecologista demandant va celebrar-ne el resultat. ${ }^{67}$ La sentència d'apel-lació ha estat considerada, igual com la del jutjat inferior, "sensacional". 68

La fonamentació de la sentència, com es pot imaginar a partir del que s'ha dit fins ara, és complexa. Principalment els reclamants es basen en el Dret intern holandès. Per començar, busquen suport a la Constitució holandesa (Grondwet), ${ }^{69}$ segons l'art. 21 (en la traducció anglesa a l'ús):

It shall be the concern of the authorities to keep the country habitable and to protect and improve the environament [De zorg van de overheid is gericht op de bewoonbaarheid van het land en de bescherming en verbetering van het leefmilieu].

La norma fonamental holandesa posa l'accent sobre el deure genèric de les autoritats de protegir i millorar el medi ambient, amb especial èmfasi en la seva habitabilitat. Una norma comparable, dit sigui de passada, existeix en moltes altres constitucions europees, com l'espanyola (art. 45), que també fa referència al deure dels poders públics de protegir el medi ambient. Amb tot, potser es podria dir que aquesta darrera va un pas més enllà, en configurar el medi ambient com un dret (art. 45.1). Convé recordar, però, que com reconeix la doctrina majoritàriament, ${ }^{70}$ no es tracta d'un veritable dret subjectiu, sinó d'una declaració de principis o programàtica, que ha d'inspirar l'actuació dels poders públics (i en tot cas no és un dret fonamental, arg. art. 53.2 CE). Per tant, des d'aquest punt de vista els punts de partida constitucionalment parlant a Holanda i Espanya són força semblants.

\footnotetext{
67 Es pot veure la nota de prensa publicada per Urgenda, "Media Release", 4.10.2018 $<$ http://files.smart.pr/c9/7d0110c7b911e8ba890b8f62b9d7b0/Urgenda-Appeal-upcomingJudgement-Oct-9th-2018-.pdf> [Darrera consulta, 16 de desembre de 2018].

68 Vegeu Jonathan Verschuuren, "Urgenda Climate Change Judgment Survives Appeal in the Netherlands", IUCN, 24 Oct 2018, <https://www.iucn.org/news/world-commission-environmentallaw/201810/urgenda-climate-change-judgment-survives-appeal-netherlands> [Darrera consulta, 16 de desembre de 2018].

${ }^{69} \mathrm{Per}$ al text en holandès: <http://wetten.overheid.nl/BWBR0001840/2017-11-17>. En anglès: $<$ https://www.government.nl/documents/regulations/2012/10/18/the-constitution-of-the-kingdomof-the-netherlands-2008> [Darrera consulta, 31 de març de 2018].

70 En aquest sentit, la interpretació en clau de veritable dret, defensada per Jesús Jordano Fraga, "El derecho a disfrutar de un medio ambiente adecuado:elementos para su articulación expansiva", Medio Ambiente \& Derecho: Revista electrónica de derecho ambiental, 1998, núm. 0, 1-11, p. 1 <https://core.ac.uk/download/pdf/51384200.pdf> [Darrera consulta: 16 de desembre de 2018] és encara aïllada.
} 
La reclamació es basa també en el Codi Civil (Burgerlijk Wetboek [BW]. Segons el seu art. 6: 142:71

1. Hij die jegens een ander een onrechtmatige daad pleegt, welke hem kan worden toegerekend, is verplicht de schade die de ander dientengevolge lijdt, te vergoeden. 2. Als onrechtmatige daad worden aangemerkt een inbreuk op een recht en een doen of nalaten in strijd met een wettelijke plicht of met hetgeen volgens ongeschreven recht in het maatschappelijk verkeer betaamt, een en ander behoudens de aanwezigheid van een rechtvaardigingsgrond.

3. Een onrechtmatige daad kan aan de dader worden toegerekend, indien zij te wijten is aan zijn schuld of aan een oorzaak welke krachtens de wet of de in het verkeer geldende opvattingen voor zijn rekening komt.

Aquesta norma és la que conté la clàusula general de responsabilitat civil per danys causats per la culpa (schuld) en el Dret holandès. El dany (schade) causat per un fet antijurídic (onrechtmatige daad) s'ha de indemnitzar (apartat 1). Per a això cal que el dany sigui atribuïble al responsable, i li és atribuïble, entre d'altres supòsits, si ha actuat amb culpa (apartat 3 ).

Per analitzar la culpa, els tribunals holandesos utilitzen l'estàndard fixat per ells mateixos. Concretament, el cas de referència és una sentència del Hoge Raad ${ }^{72}$ de l'any 1965, relativa a uns danys causats per una caiguda d'un client d'un bar a través de la trapa d'un soterrani (el cas és conegut precisament així, com el cas de la trapa o kelderluik arrest). ${ }^{73}$ Va succeir en aquest cas que el visitant del bar es va dirigir cap als serveis del mateix i, de camí, va caure per la trapa que el transportista d'una empresa subministradora de begudes havia deixat oberta de manera negligent. Segons el tribunal, una persona que es dirigeix cap al lavabo quan es troba en un bar no té per què anar mirant tot el temps cap a terra, mentre que el transportista té el deure de preveure que algú pot caure-hi a través. L'interessant del cas Urgenda és que el tribunal de La Haia es va basar precisament en l'anàlisi de la culpa per fer a l'Estat holandès corresponsable del canvi climàtic, sobre aquesta base. Convé per això aturar-se en aquest aspecte

\footnotetext{
${ }^{71}$ Es maneja el text actualitzat següent: <http://wetten.overheid.nl/BWBR0005289/2017-09-01> [Darrera consulta, 16 de desembre de 2018].

72 Les seves resolucions a text complet es troben a: <https://www.rechtspraak.nl/Organisatie-encontact/Organisatie/Hoge-Raad-der-Nederlanden> [Darrera consulta, 16 de desembre de 2018]. 73 Vegeu-lo a: Hoge Raad [HR] 6 november 1965, Nederlandse Jurisprudentie [NJ] 1966,136.
} 
de l'anàlisi del deure de diligència (zorgvuldigheidsplicht o, en la traducció anglesa, duty of care), encara que sigui breument. Els elements a tenir en compte, segons el tribunal, són:

a) la naturalesa i l'abast del dany derivat del canvi climàtic;

b) el coneixement i previsibilitat d'aquest dany. Cal tenir en compte, en aquest sentit, el coneixement científic derivat del panell IPCC, i així ho entén el tribunal; c) Ia probabilitat que un canvi climàtic perillós tingui lloc. En efecte, els danys poden ser catastròfics (com ja va ser posat de manifest en un cas nord-americà, Massachusetts v. EPA, 2006); $;^{74}$

d) la naturalesa dels actes (o omissions) de l'Estat holandès. De fet, aquest Estat està subvencionant les emissions des del punt de vista econòmic. A més, si bé és cert que l'Estat holandès emet relativament poc si es tenen en compte les emissions d'altres països, les seves emissions són desproporcionadament grans pel que és el país;

e) el caràcter onerós o no d'adoptar mesures de precaució;

f) la discreció de l'Estat a l'hora d'executar els seus deures públics. Referent a això, el tribunal considera que l'Estat no té discrecionalitat per complir o no aquests deures, ja que ha assumit un compromís internacional de reduir les seves emissions. Concretament, l'Estat holandès s'ha fixat com a objectiu internament una reducció del 16\% de les emissions l'any 2020 (en comptes del $25 \%$ a què s'ha compromès en el pla internacional). Salta a la vista que, donada aquesta diferència de 9 punts percentuals, el citat Estat està incomplint aquells deures.

Els arguments de la defensa d l'Estat holandès van ser diversos:

a) En primer lloc, l'Estat minimitza la seva participació en la causa del suposat mal. En efecte, I a contribució d'Holanda al canvi climàtic és molt petita si se la compara amb altres molts països de majors dimensions. Es tracta, doncs, de l'argument de minimis, basat en la pressuposició que qui contribueix poc a causar un dany no ha de respondre.

b) També al-lega en defensa seva que l'Estat no és causant de les emissions que tenen lloc al seu territori. Per descomptat, es tracta d'emissions causades per subjectes privats situats en el mateix, però no per l'Estat com a tal.

${ }^{74}$ Massachusetts v. Environmental Protection Agency, 549 US 497 (2007). 
c) També al-lega l'Estat holandès que cap norma internacional l'obliga a assolir els objectius de reducció de les emissions.

d) Finalment, Holanda s'empara en el principi de la separació de poders (machtenscheiding, trias politica). Per a l'Estat holandès, el tribunal no és competent per valorar una actuació de l'Estat, perquè altrament això constituiria una interferència amb les seves atribucions.

Després de valorar totes aquestes consideracions, el tribunal va condemnar I'Estat holandès, sobre la base dels següents arguments:

a) L'Estat holandès té un deure de diligència (zorgvuldigheidsplicht), deure que es basa en l'art. 6:102 BW, per tant, en una norma jurídica-civil sobre responsabilitat civil. Aquest deure ha quedat infringit per l'actuació de l'Estat, que no ha actuat amb la diligència deguda.

b) És cert que els ciutadans no poden basar-se en el Protocol de Kyoto directament per exigir a l'Estat que compleixi amb els seus compromisos internacionals, però aquest acord sí que defineix el deure de diligència de l'Estat, al qual s'acaba de fer referència. Aquest tipus d'acords esdevenen rellevants, ja que permeten determinar com s'ha de comportar l'Estat, fins i tot en el cas en què no siguin vinculants jurídicament. ${ }^{75}$

c) L'Estat holandès té un deure constitucional de protegir el medi ambient (art. 21 Grondwet), com ja s'ha dit més amunt.

d) És irrellevant que la contribució d'Holanda al canvi climàtic sigui comparativament petita.

e) El Dret holandès no coneix una separació completa entre els poders de l'Estat. Cada poder té les seves responsabilitats, però l'actuació dels òrgans polítics pot ser examinada pels jutges de manera independent. Rebutja, en fi, l'argument de la trias politica.

L'argumentació del tribunal holandès resulta molt interessant, en la mesura en què juxtaposa instruments normatius nacionals i internacionals. L'Estat holandès està obligat a reduir les emissions que contribueixen al canvi climàtic sobre la base d'un mix de normes, entre les quals n'hi ha de caràcter internacional (com el Protocol de Kyoto) i d'altres d'internes o nacionals (com el Codi Civil). No cal

\footnotetext{
75 Vegeu Roger Cox, "A climate change litigation precedent: Urgenda Foundation $v$ The State of the Netherlands", Journal of Energy \& Natural Resources Law, vol. 34, núm. 2, 2016, 143-163, p. 147.
} 
que una norma concreta obligui l'Estat holandès a reduir les emissions, sinó que aquesta conseqüència es pot extreure per via interpretativa mitjançant l'aplicació de normes civils sobre responsabilitat. ${ }^{76}$

\section{Altres casos}

a) El cas Klimaatzaak

En molt poc temps, Urgenda ha demostrat ser un model fructífer. L'exemple més clar que es coneix és el cas Klimaatzaak, ${ }^{77}$ que s'ha plantejat a Bèlgica. Klimaatzaak és el nom d'una ONG amb seu a Bèlgica, que va plantejar a l'abril de 2015 una demanda a imatge i semblança de la que va triomfar al seu país veí. En essència, la reclamació -interposada per l' associació i gairebé 50.000 persones més, segons dades extretes de la seva pàgina a Internet- demana al Govern belga i a les autoritats regionals que redueixin les emissions de gasos d'efecte hivernacle en l'horitzó de 2020. Es basa en la jurisprudència del TEDH (casos Boudayeva v. Russia78 i Öneryildiz v. Turkey) 79 i del Tribunal Internacional de Justícia (cas Pulp Mills), concretament en relació amb el principi de prevenció. Alguns autors ja han pronosticat el mateix resultat que en el cas Urgenda. ${ }^{80} \mathrm{La}$ referència al principi de prevenció resulta interessant, car no és del tot evident que doni suport a la reclamació. En aquest sentit, s'ha posat en relleu que el fet que la ja referida International Law Association es recolzi en el principi de prevenció en relació amb la lluita contra el canvi climàtic resulta inadequat. ${ }^{81}$ En qualsevol cas, crida l'atenció que l'associació Klimaatzaak fos fundada per advocats belgues però també holandesos. El vincle amb Urgenda sembla evident.

\footnotetext{
76 Semblantment, vegeu Noel Rodríguez García, "Responsabilidad del Estado y cambio climático: el caso Urgenda c. Países Bajos", Revista Catalana de Dret Ambiental, vol. 7, núm. 2, 2016, 1-38, p. 18.

77 Es pot veure la pàgina sobre el cas a Internet: <https://www.klimaatzaak.eu/nl/the-case> [Darrera consulta, 16 de desembre de 2018].

78 Applications ens. 15339/02, 21166/02, 20058/02, 11673/02 i 15343/02, 20 març 2008 $<$ https://hudoc.echr.coe.int/eng?i=001-85436> [Darrera consulta, 16 de desembre de 2018].

79 Application no. 48939/99, 30 novembre 2004 <http://www.globalhealthrights.org/wpcontent/uploads/2013/02/ECtHR-2004-Oneryildiz-v-Turkey.pdf> [Darrera consulta, 16 de desembre de 2018].

80 Vegeu Cox, "A climate change litigation precedent...", cit., p. 147.

81 Vegeu Alexander Zahar, "Mediated versus Cumulative Environmental Damage and the International Law Association's Legal Principles on Climate Change", Climate Law, vol. 4, núm. 3-4, 2014, 217-233, p. 226.
} 
b) Els casos Washington Kids i Juliana

Un altre cas de referència és Zoe and Stella Foster et al. v. Washington Department of Ecology, ${ }^{82}$ conegut de manera abreujada com "cas Washington Kids". Deu aquest nom al fet que els demandants van ser 8 menors d'edat, que van demanar al Departament d'Ecologia del dit Estat una reducció més ambiciosa de les emissions de gasos d'efecte hivernacle. El Governador de l'Estat va reconèixer que la petició era vàlida, però li va demanar al tribunal que la desestimés. La resolució es refereix al deure o canon de diligència (duty of care), com en el cas Urgenda, i a la public trust doctrine, una doctrina que permet entendre que determinats béns col-lectius estan tutelats o protegits per l'Estat a títol fiduciari.

Molt semblant a l'anterior és el cas Kelsey Juliana, plantejat també als EUA ${ }^{83}$ En aquest altre litigi, un total de vint-demandants, més I'ONG Earth Guardians ${ }^{84}$ i un professor de la Universitat de Columbia, el Dr. James E. Hansen ${ }^{85}$ (com a guardià de les generacions futures), van demandar als EUA, el president del país, i a diversos funcionaris d'agències federals i les agències mateixes. L'objecte de la demanda era sol-licitar una indemnització per haver promogut el canvi climàtic. A l'abril de 2016, el tribunal d'Oregon davant el qual es va interposar la demanda la va desestimar; tanmateix, va fer al-lusió al duty of care o deure de cura dels demandats.

\section{c) El cas Leghari}

El cas que es resumeix a continuació té la peculiaritat d'estar situat fora d'Europa, concretament al Pakistan. Ashgar Leghari, ciutadà d'aquest país, ${ }^{86}$ va interposar

82 Order No. 14-2-25295-1 SIGUI, 19 November 2015, Superior Court of the State of Washington for King County <https://static1.squarespace.com/static/571d109b04426270152febe0/t/57607fe459827eb8741a 852c/1465941993492/ 15.11.19.Order_FosterV.Ecology.pdf> [Darrera consulta, 16 de desembre de 2018].

${ }^{83}$ Kelsey Juliana et al. v. The United States of America et al., Casi number 6: 15-cv-01517-TC, Order and Findings and Recommendation, 8 April 2016, United States District Court, District of Oregon - Eugene Division <https://static1.squarespace.com/static/571d109b04426270152febe0/ t/5824e85e6a49638292ddd1c9/1478813795912/Order+MTD.Aiken.pdf> [Darrera consulta, 16 de desembre de 2018].

${ }^{84}$ Vegeu la seva pàgina a Internet <https://www.earthguardians.org/> [Darrera consulta, 16 de desembre de 2018].

85 Es pot veure la seva pàgina al web d'aquesta universitat: <http://www.columbia.edu/ jeh1/> [Darrera consulta, 16 de desembre de 2018].

${ }^{86}$ Es pot veure el seu perfil a Twitter: <https://twitter.com/asgharleghari> [Darrera consulta, 16 de desembre de 2018]. 
a l'agost de 2015 una demanda contra el Govern federal del Pakistan i el Govern provincial del Panjab, en què els exigia que desenvolupessin la política nacional sobre canvi climàtic (aprovada el 2012), en relació amb l'adaptació a noves formes d'energia. ${ }^{87}$ La demanda planteja que el canvi climàtic suposa un risc per a la seguretat dels aliments i l'aigua al Pakistan. Cal tenir en compte que, per raons geogràfiques, el país és especialment sensible al canvi climàtic i es pot veure molt afectat en el subministrament d'aigua si el canvi climàtic va a pitjor. ${ }^{88}$ El Tribunal Superior de Lahore (Lahore High Court Green Bench) va estimar la demanda el 4 de setembre de 2015 i va concloure que la passivitat de l'Estat vulnera els drets fonamentals dels seus ciutadans. En conseqüència, va ordenar les seves autoritats que implementessin la dita política. Pel que fa al fonament de la sentència, es basa una vegada més en la ja esmentada public trust doctrine.

\section{d) El cas de les illes Lofoten}

Amb el cas següent tornem a Europa, concretament a Noruega. Es tracta d'una demanda interposada per tres ONG, totes les quals adopten jurídicament la forma d'associació. Es tracta concretament de la divisió noruega de Greenpeace (Greenpeace Norge), 89 Natur og Ungdom, 90 i Besteforeldrenes klimaaksjon. ${ }^{91}$ L'acció judicial es planteja contra l'Estat i els departaments de Petroli i d'Energia (Staten vegeu Olje-og energidepartementet) de l'Estat noruec. ${ }^{92} \mathrm{El}$ cas ha estat resolt fa poc pel tribunal de primera instància d'Oslo (Oslo Tingrett). La situació que dona peu a la demanda és la següent. El Parlament noruec havia permès la perforació petrolífera fora de Lofoten (al mar de Barents), el 10 de juny del 2016.

\footnotetext{
87 La informació sobre el cas pot trobar-se a: $<$ http://www.Ise.ac.uk/GranthamInstitute/litigation/ashgar-leghari-v-federation-of-pakistanlahore-high-court-green-bench-2015/> [Darrera consulta, 16 de desembre de 2018].

88 Vegeu Nadia B. Ahmad / Mushtaq ur Rasool Bilal, "Monsoons, Hydropower, and Climate Justice in Pakistan 's River Communities", en Randall Abate, Climate Justice: Case Studies in Global and Regional Governance Challenges, West Academic. Washington, 2016, 471-492, p. 474.

${ }^{89}<\mathrm{http}: / /$ www.greenpeace.org/norway/no/> [Darrera consulta, 16 de desembre de 2018].

$90<$ https://nu.no/> [Darrera consulta, 16 de desembre de 2018]. El nom de l'organització significa "Natura i joventut".

91 <http://www.besteforeldreaksjonen.no/> [Darrera consulta, 16 de desembre de 2018]. Aquesta tercera entitat es va adherir al procés.

92 La demanda va ser interposada el 6 de novembre de 2017 i es troba a $<$ https://www.domstol.no/contentassets/b4dfee3a8be84970a677066bc60041f3/sluttinnlegg_gre enpeace_naturogungdom.pdf> [Darrera consulta, 16 de desembre de 2018].
} 
Segons el parer de les organitzacions demandants, aquesta autorització administrativa vulnera la Constitució noruega, la qual protegeix el medi ambient en aquests termes (art. 112):

Every person has the right to an environment that is conducive to health and to a natural environment whose productivity and diversity are maintained. Natural resources shall be managed on the basis of comprehensive long-term considerations which will safeguard this right for future generations as well.

L'advocat de l'Estat noruec havia argumentat que aquesta norma no legitima activament els subjectes privats per a reclamar enfront de l'Estat. És remarcable que la demanda el que fa és qüestionar la legalitat de l'autorització administrativa, però sense demanar una indemnització per danys.

El cas ha conclòs amb una sentència desestimatòria, de data 4 de gener de 2018, sentència que a més ha imposat als demandants les costes del procés (580.000 corones noruegues, l'equivalent a uns $60.600 €$ ). La sentència, el text íntegre (en noruec) de la qual pot consultar-se en línia, ${ }^{93}$ conclou que la decisió de concessió administrativa del permís d'explotació petroliera, que era el fons de la qüestió, és vàlida, i les raons esgrimides per les associacions demandants no són suficients per a sostenir la conclusió contrària. ${ }^{94}$

Segons una nota de premsa de Greenpeace Norge, el tribunal d'Oslo dona la raó només parcialment a les associacions demandants i acaba absolent a l'Estat, tot i que aquelles consideren que la fonamentació d'aquesta part de la decisió és errònia. El procés, segons les organitzacions ecologistes, ha servit, amb tot, per augmentar la conscienciació sobre el caràcter equivocat o erroni —al seu judicide la política del govern noruec que l'acció judicial pretenia posar en qüestió. ${ }^{95}$ Almenys una de les tres associacions ja s'ha expressat en el sentit de voler recórrer la sentència en apel·lació. ${ }^{96} \mathrm{El}$ cas posa en relleu el greu risc que pateixen les associacions ecologistes que es plantegin tirar endavant amb litigis climàtics. El fet de perdre el judici es pot considerar menor en relació amb el

static.greenpeace.org/norway/Global/norway/Arktis/bilder/2017/Dom\%20Klimars\%C3\%B8ksma $\%$ CC\%8Alet.pdf> [Darrera consulta, 16 de desembre de 2018].

94 Apartat 5.3.7 de la sentència, pàg. 45 de l'original.

95 Vegeu la nota de premsa (Pressemelding) Greenpeace Norway, "Tingretten frifinner staten ", 2018.04.01 <http://www.greenpeace.org/norway/no/Tingretten-frifinner-staten/> [Darrera consulta, 16 de desembre de 2018].

96 Vegeu Besteforeldrenes Klimaaksjon, "Klimadommen Bor ankes", 2018.01.21 $<$ http://www.besteforeldreaksjonen.no/?p=42073> [Darrera consulta, 16 de desembre de 2018]. 
problema que suposa haver d'assumir-ne les quantioses costes processals. La condemna en costes es pot convertir, en efecte, en un important desincentiu per a reclamar.

\section{e) El cas KlimaSeniorinnen}

També es pot fer referència a una reclamació interposada per diverses senyores d'edat avançada a Suïssa. Les reclamants, agrupades en l'associació KlimaSeniorinnen Schweiz, ${ }^{97}$ que té la seva seu a Zuric, ${ }^{98}$ al-leguen que les autoritats helvètiques han adoptat una política inadequada en matèria ambiental, i per tant deixat de complir amb el deure constitucional de protegir el medi ambient. De manera similar a altres reclamacions referides més amunt, es basen no només en el Dret intern, sinó també en la suposada vulneració de drets humans, tenint en compte que Suïssa és membre de la Convenció Europea de Drets Humans. Concretament, les ancianes suïsses es queixen que constitueixen un col-lectiu especialment vulnerable i que l'incompliment per les autoritats suïsses posa en perill la seva salut i la seva vida. ${ }^{99}$ Part de la doctrina suïssa ha posat en relleu que la reclamació té una base sòlida i que poden esperar-se altres reclamacions anàlogues en el futur. ${ }^{100}$

\section{ANÀLISI I PERSPECTIVES DE FUTUR}

La pregunta lògica que cal plantejar-se després de l'examen precedent és: i ara què? Cal interrogar-se per les perspectives de futur, en particular, sobre quin serà el resultat d'aquestes demandes "a la Urgenda". Per això resulta convenient abans analitzar críticament aquesta sentència.

En primer lloc, sembla evident que el cas Urgenda fixa un exemple, un model a seguir per altres països (com acrediten els casos esmentats). Entre les seves

97 Se'n pot veure la página web a <https://klimaseniorinnen.ch/> [Darrera consulta, 16 de desembre de 2018].

98 Vegeu-ne els estatuts a <https://klimaseniorinnen.ch/wpcontent/uploads/2016/08/2016_Statuten_KlimaSeniorinnen-Schweiz_def.pdf > [Darrera consulta, 16 de desembre de 2018].

${ }^{99}$ Així ho ha manifestat una de les seves advocades, Ursula Brunner, als mitjans de comunicació. Vegeu Elsbeth Gugger, "Klimaklage in den Niederlanden wirkt bis in die Schweiz", SRF, 26.10.2016, <https://www.srf.ch/news/schweiz/klimaklage-in-den-niederlanden-wirkt-bis-in-dieschweiz> [Darrera consulta, 16 de desembre de 2018].

100 Vegeu Cordelia Christiane Bähr / Ursula Brunner / Kristin Casper / Sandra H Lustig, "KlimaSeniorinnen: lessons from the Swisssenior women's case for future climate litigation", Journal of Human Rights and the Environment, vol. 9, núm. 2, 2018, 194-221, p. 194. 
bondats o virtuts cal incloure el fet que hagi estimulat el debat sobre el canvi climàtic i el paper dels estats. Sens dubte, ha donat certa publicitat al problema, si més no en l'àmbit doctrinal ambientalista i entre les organitzacions ecologistes. ${ }^{101}$

A més, la traducció de sengles sentències a l'anglès (i especialment de la primera d'elles) sens dubte ha potenciat la seva influència internacional. No sembla habitual que un país on l'anglès no és la llengua oficial faci traduir a aquesta una sentència en què resulti condemnat i la publiqui a Internet, a l'abast de tothom. Fins i tot, el fet que l'Estat holandès apel-lés la sentència no ha estat obstacle perquè ja hagi millorat les seves mesures en el sentit de combatre el canvi climàtic. En aquest sentit, la conducta de l'Estat holandès sembla paradoxal, ja que si és conscient que calia que millorés en aquest sentit podria no haver impugnat la sentència. D'una banda sembla que l'acata, i de l'altra l'ataca.

Això últim ja podria constituir, per si sol, un motiu de celebració per a l'organització ecologista Urgenda. No obstant això, hi ha alguna cosa que probablement sorprengui, com és que el procés no conclou amb una condemna a indemnitzar un dany. En efecte, no es demana una indemnització, sinó que es condemna l'Estat holandès a complir els seus compromisos internacionals $\mathrm{i}$, per tant, a fer més per tal de combatre el canvi climàtic en el seu territori. Això és així perquè el Dret holandès permet de demanar aquest tipus de remei, no indemnitzatori, mitjançant el procés civil.

Fins $\mathrm{i}$ tot es podria qüestionar-se si el remei indemnitzatori, propi de la responsabilitat civil, és el més adequat en aquests casos. Hi ha qui entén que no, perquè la indemnització causaria més mal que bé. ${ }^{102}$ Per descomptat, un excés d'emissions de gasos d'efecte hivernacle constitueix una vulneració d'un o de diversos drets humans. No obstant això, una indemnització de tots els danys o plena excedeix les capacitats financeres de (gairebé) totes les empreses i Estats. ${ }^{103}$ En efecte, en alguna ocasió s'ha suggerit que no convé reclamar contar les empreses, ja que la conducta d'aquestes està reconeguda 0

101 Vegeu Ch. W. Bakkes, "Noot", AB Rechtspraak Bestuursrecht, núm. 336, 2015, 2112-2116, p. 2112.

102 Vegeu Jaap Spier, "Injunctive relief", en Jaap Spier / Ulrich Magnus (eds.), Climate change remedies: injunctive relief and criminal law responses, Eleven International. The Hague, 2014, 1120 , p. 5.

103 Vegeu Spier, Shaping the law ..., cit., p. 43. 
autoritzada pels Estats i només aquests tenen el múscul financer suficient per fer front a les hipotètiques reparacions. ${ }^{104}$ Tanmateix, és possible que ni tan sols els Estats disposin dels recursos suficients per a assumir una càrrega tan feixuga. Apart del fer que els Estats es nodreixen fonamentalment dels recursos que obtenen via impostos de la seva ciutadania $i$, per tant, demandar-los no suposa res més que traslladar a aquesta els costos dels danys que ella mateixa pateix. Causar fallides massives i destruir el sistema econòmic, el que s'assenyala com un efecte possible de començar a exigir indemnitzacions, no serviria per resoldre el problema, segons es creu. ${ }^{105}$ Per això, s'ha assenyalat que la indemnització de danys no és el remei per al canvi climàtic.

Tanmateix, això sembla que introdueix en el debat sobre la responsabilitat consideracions que en part en són alienes, això és, les relatives a les conseqüències de les seves aplicacions. Almenys en els sistemes de l'anomenat civil law, no resulta habitual que els tribunals introdueixin en les seves argumentacions raons de política jurídica o policy, en les quals es doni pes a les hipotètiques conseqüències $\mathrm{o}$ resultats de les seves decisions. ${ }^{106}$ Les condemnes de responsabilitat civil tenen lloc encara que portin a la fallida dels que en resulten condemnats. Hom es podria preguntar, doncs, si l'abast de les potencials condemnes de responsabilitat pel canvi climàtic podrien, tal vegada, canviar aquest plantejament, o si bé els jutges han de seguir com fins ara: condemnar, i pereat mundus!

Front de l'anterior, convé preguntar-se si realment el risc de fallida és tan gran o evident com es sembla creure. Més aviat, sembla que els obstacles per a la indemnització són abundants. En aquest sentit, el nexe causal-com s'ha dit més amunt- és considerat per alguns com el principal escull per a la responsabilitat pel canvi climàtic. Els problemes d'incertesa es donen tant del costat del demandant (situació que en llengua anglesa es coneix com a "demandant

\footnotetext{
104 Vegeu Hall, "State Responsibility...", cit., p. 220.

105 Vegeu Roger H.J. Cox, Revolution Justified, Planet Prosperity Foundation. Maastricht, 2012, p. 267.

106 Una excepció recent és la polèmica sobre qui havia de suportar l'Impost sobre actes jurídics documentats en el cas de les hipoteques, en la qual el Tribunal Suprem sembla que ha fet prevaldre l'impacte financer que una decisió contra la banca hauria tingut sobre el mercat. Vegeu al respecte Expansión, "Guía para entender la decisión del Supremo sobre el impuesto de las hipotecas", 7.11.2018 <http://www.expansion.com/empresas/banca/2018/11/07/5be1ff27268e3e67058b466f.html> [Darrera consulta, 16 de desembre de 2018].
} 
indeterminat" 0 indeterminate plaintiff) com del demandat (indeterminate defendant). ${ }^{107}$ Potser és massa aviat per establir un nexe causal ferm entre les emissions de gasos d'efecte hivernacle i els danys. Segons sembla, la ciència encara no ha avançat prou com per vincular un desastre natural específic al canvi climàtic. ${ }^{108}$ En aquest sentit, el canvi climàtic està encara envoltat d'una gran incertesa. ${ }^{109}$ Però sembla necessari que aquesta incertesa no comporti la paràlisi o l'abstencionisme per part del Dret, i que aquest busqui maneres per a poder actuar per a contribuir a resoldre aquesta problemàtica. ${ }^{110}$

De fet, el coneixement que se'n té actualment hauria de ser suficient almenys per obtenir protecció cautelar o provisional, el que en llengua anglesa es coneix com injunctive relief. ${ }^{111}$ Almenys es podria reclamar una protecció cautelar, per la via de l'acció negatòria (en la seva vessant d'acció de cessació) sobre la base de l'amenaça de desastres naturals - com huracans, tornados o similars- en general. ${ }^{112}$ Així ho ha entès el tribunal d'apel·lació en el cas Urgenda, per al qual el requisit de la causalitat no és realment un problema, ja que el que està en tela de judici no és una indemnització de danys, sinó la qüestió de si s'ha de posar o no en pràctica una determinada política, i en aquest sentit és suficient amb la constatació que existeix un risc real en relació amb el qual cal adoptar mesures. En qualsevol cas, una reclamació basada en el patró d'Urgenda es veu afavorida per l'estat actual de coses en el Dret ambiental en general, i en relació amb el canvi climàtic en particular. El Dret sobre el canvi climàtic actual adopta un enfocament bottom up (de baix a dalt) que afavoreix el paper dels Estats nacionals. Amb això, obre la porta a reclamacions d'aquest tipus.

$A$ això cal afegir l'absència de tribunals internacionals o mundials sobre el canvi climàtic. Els tribunals nacionals són un fòrum interessant per a discutir-hi aquest

\footnotetext{
107 Vegeu Erik Pöttker, Klimahaftungsrecht. Die Haftung für die Emission von Treibhausgasen in Deutschland und den Vereinigten Staaten von Amerika, Mohr Siebeck. Tübingen, 2014, p. 61. 108 Vegeu Spier, Shaping the law ..., cit., p. 55 i 91.

109 Vegeu L. Mark Berliner, "Uncertainty and Climate Change", Statistical Science, vol. 18, núm. 4, 2003, 430-435, p. 433.

110 De manera similar, fent una crida a la col-laboració internacional, es pot veure Xiao-Bing Zhang / Magnus Hennlock, "The benefits of international cooperation underclimate uncertainty: a dynamic game analysis", Environment and Development Economics, núm. 23, 2018, 452-477, p. 452.

111 Vegeu Spier, Shaping the law ..., cit., p. 56.

112 Així, Spier, "Injunctive relief", cit., p. 19.
} 
assumpte. ${ }^{113}$ En aquesta línia, la feblesa de les institucions internacionals que suposadament se n'haurien d'encarregar d'abordar i resoldre els problemes ambientals planetaris ${ }^{114}$ és un factor que pot explicar la deriva cap a un major èmfasi en el pla nacional o local.

Des de la perspectiva de la legitimació activa (o locus standi, com es diu en llengua anglesa), es tracta — segons s'ha vist amunt- de reclamacions plantejades per ONG i ciutadans. No es tracta d'una víctima tradicional, sinó que els que reclamen el es mouen sovint per defensar el medi ambient en general, 0 la col-lectivitat en el seu conjunt. Aquest tipus d'actuació està emparada per la Convenció d'Aarhus de 1998. ${ }^{115}$

No obstant això, aquesta Convenció ha estat rebuda de maneres molt diferents segons els països de la Unió Europea. Hom podria preguntar-se per això si la reclamació tindria el mateix èxit en tots ells. Alguna opinió doctrinal ha vaticinat que en el Dret espanyol seria possible una reclamació tipus Urgenda. ${ }^{116} \mathrm{Com}$ apunta un dels decisius impulsors de la demanda holandesa, tots els Estats tenen un deure d'actuar diligentment, i l'estàndard de la culpa és universal. ${ }^{117}$

En el cas d'Espanya, a més, l'Estat respon objectivament o sense culpa, tal com preveu la Llei del sector públic (art. 32). ${ }^{118}$ La qüestió sembla més dubtosa en altres sistemes -com l'alemany- on les associacions ecologistes potser no són tan actives en aquest sentit com les holandeses. De fet, tampoc a Espanya no hi ha hagut cap reclamació d'aquest tipus encara, però se'n té notícia que se n'està preparant una. ${ }^{119}$

En aquest sentit, es dona la circumstància que la crisi ha afavorit, si es pot dir així, l'Estat espanyol, car la disminució de l'activitat econòmica ha facilitat que

\footnotetext{
113 Vegeu Tracy Bach, "Human Rights in a Climate Changed World: The Impact of COP21, Nationally Determined Contributions, and National Courts", Vermont Law Review, vol. 40, 2016, 561-595, p. 566.

114 Vegeu al respecte Olabe, Crisis climática-ambiental, cit., p. 25.

115 Aarhus Convention (1998): Convention on Access to Information, Public Participation in Decision-Making and Access to Justice in Environmental Matters.

116 Vegeu Paz de Vilchez Moragues, "Broadening the scope: The Urgenda case, the Oslo Principles and the role of national courts in advancing environmental protection concerning climate change", Spanish Yearbook of International Law, núm. 20, 2016, 71-92, p. 88.

117 Vegeu R.H.J. Cox, "The Liability of European States for Climate Change", Utrecht Journal of International and European Law, vol. 30, núm. 78, 2014, 125-135, pàg. 129.

118 Ley 40/2015, de 1 de octubre, de Régimen Jurídico del Sector Público (BOE núm. 236, de 02/10/2015).

119 Se'n va donar notícia durant el debat en una de les sessions del Congrés català sobre canvi climàtic a la Universitat Rovira i Virgili (Tarragona) el gener de 2018.
} 
temporalment es complissin els compromisos de reducció dels nivells d'emissió de gasos d'efecte hivernacle. Per això, el primer escull de la hipotètica reclamació consistiria en demostrar l'incompliment dels esmentats compromisos, sense el qual difícilment es podria fer responsable l'Estat. En tot cas, resulta important no perdre de vista l'instrument de la responsabilitat de l'Estat si s'aconsegueix demostrar aquest incompliment, car no només es pot comptar amb els instruments propis del Dret públic. ${ }^{120}$

Un altre aspecte a tenir en compte és que moltes de les normes al-legades com a base de les demandes imposen obligacions entre Estats, no front de subjectes privats (com és el cas d'Urgenda i la resta de demandants). Això planteja un problema interessant, que té una dimensió evident de Dret internacional. Els Estats s'obliguen entre si, en la suposició que cap subjecte privat els exigirà el compliment d'aquestes obligacions. Els tractats internacionals normalment no tenen mecanismes d'enforcement o aplicació coactiva, la qual cosa contribueix a agreujar aquest problema. Per altra banda, la separació de poders no justifica la violació del Dret nacional i internacional i dels drets humans. ${ }^{121}$ Per tant, un Estat no pot escudar-se en la ja referida separació de poders o trias politica per eludir les seves obligacions internacionals i justificar així una vulneració dels drets humans. En aquest sentit, la vella doctrina dels "actes polítics" difícilment podria evitar que un jutge entrés a analitzar si la conducta del govern ha estat $o$ no conforme a Dret.

Una qüestió diferent és si la sentència Urgenda realment enfoca bé la qüestió de fons. Tot el cas gira entorn a la pregunta es si l'Estat holandès va poder fer més del que estava fent efectivament per a lluitar contra el canvi climàtic. No obstant això, si el que està en joc és l'anàlisi de si l'Estat holandès va complir amb el seu deure de diligència, la qüestió no és si es podia haver fet més, sinó si es va obrar bé. ${ }^{122}$ Per tant, no calia centrar-se en si podia haver reduït més les emissions, sinó si estava fent el suficient en relació amb els compromisos internacionalment assumits.

\footnotetext{
${ }^{120}$ Sobre aquests darrers, vegeu Estanislao Arana García, "The Fight Against Climate Change in Spain”, European Energy and Environmental Law Review, vol. 20, núm. 5, 2011, 176-186, p. 176 sS.

121 Vegeu Bob Bakker, "Urgenda: International law, Dutch policies and the separation of powers", Medium, 2016, <https://medium.com/@bojbakker/urgenda-international-law-dutch-policies-andthe-separation-of-powers-ee8277735d0a> [Darrera consulta, 16 de desembre de 2018]. 122 Vegeu Bakkes, "Noot", cit., p. 2114, entre d'altres autors.
} 
Així doncs, el que importa no és si l'Estat holandès podria o no haver adoptat més precaucions, sinó si va actuar amb culpa o no. El matís pot ser que sigui molt fi, però hi és. Des d'aquest punt de vista, es pot suggerir que l'anàlisi del jutge hauria d'haver estat si els nivells de compliment determinats internament per l'Estat holandès eren negligents o no. Això dona a entendre que un nivell aparentment inferior al reclamat internacionalment no necessàriament es podria considerar culpós, com en canvi han fet els jutges holandesos.

Un altre problema de la sentència Urgenda és que l'anàlisi que du a terme del tema de la causalitat és insuficient. Caldria, en aquest sentit, veure què hi diu, el Dret intern holandès, sobre el nexe de causalitat. Per al Dret holandès no és suficient basar-se en un concepte de la causalitat en el sentit natural (o causalitat en el sentit de la conditio sine qua non o teoria de l'equivalència de les condicions), sinó que faltaria també analitzar l'anomenada relativiteit. ${ }^{123}$ Es tracta d'un segon pas o estadi en l'anàlisi de la causalitat, que encara que no existeixi en altres ordenaments (com l'espanyol, per exemple), s'ha d'analitzar per part del jutge en el Dret holandès, ja que està prevista pel Codi civil corresponent (art. 6:103). Es tracta, en suma, d'escatir si l'interès suposadament afectat està protegit per la norma que se suposa que s'ha infringit (criteri del fi protector de la norma, el que en Dret espanyol equivaldria a un criteri d'imputació objectiva).

D'altra banda, fins i tot des d'un punt de vista estrictament causal, el canvi climàtic és un fenomen intrínsecament pluri- o multicausal. No es pot atribuir tot el dany només a l'Estat, o a un Estat en concret. L'anàlisi del tribunal holandès resulta, per això, reduccionista, en no tenir en compte el paper d'infinites altres causes al fenomen del dany climàtic. No es pot oblidar que la incertesa és una dificultat recorrent en relació amb les qüestions del canvi climàtic, ${ }^{124}$ incloent-hi la causalitat.

El debat pot centrar-se també en un altre aspecte, com és el de l'activisme judicial. Pot donar la impressió que en el fons l'èxit o fracàs de l'acció depèn exclusivament del criteri libèrrim del jutge de què es tracti. En efecte, molt depèn en bona mesura de la flexibilitat amb què els jutges interpretin i apliquin el Dret

123 Vegeu Bakkes, "Noot", cit., p. 2113.

124 Vegeu Nicholas de Sadeleer, "The Precautionary principle and climate change", en Daniel A. Farber / Marjan Peters (ed.), Climate Change Law. Elgar Encyclopedia of Environmental Law, Elgar. Cheltenham, 2016, 20-31, p. 21. 
vigent. ${ }^{125}$ Però el debat sobre la separació de poders és sens dubte un que pot transcendir l'àmbit concret d'aquest cas i que té implicacions molt profundes.

La qüestió de fons en el cas Urgenda i tots els altres que estan tallats segons el mateix patró, és que ens trobem front d'una qüestió política, però també jurídica (ja que es refereix a l'anàlisi de l'element culpa). ${ }^{126}$ Fins a quin punt l'Estat acaba sent considerat o no responsable depèn dels jutges nacionals. Però precisament el que convé establir és si pot un jutge entrar en aquest tipus de qüestions. En el cas Urgenda, el que succeeix és que s'instrumentalitza el Dret de la responsabilitat civil per interferir amb la regulació de riscos duta a terme per I'Administració pública. ${ }^{127}$ La responsabilitat civil es converteix així en un mitjà per contraatacar en cas de passivitat de l'Estat en relació amb riscos per a la salut o el medi ambient. ${ }^{128}$

Enfocat des d'una altra perspectiva, es fa servir la litigació climàtica com una eina per a intervenir en la confrontació política. Es posa així l'Estat contra les cordes per una política discutible o directament errònia, amb l'ajut dels tribunals.

Aquesta dimensió de la litigació climàtica permet posar en relleu que no ens trobem en absolut davant d'un tema estrictament jurídic. La litigació climàtica s'està fent servir per a traslladar als tribunals un debat polític. Resulta dubtós que aquest fenomen es pogués extrapolar a altres ordenaments on els jutges són, potser, menys donats a posicionar-se activament en assumptes amb un clar rerefons polític. En efecte, el altres ordenaments, com l'alemany, la doctrina ja ha assenyalat que es tracta d'una qüestió constitucional, vetada al jutge ordinari. ${ }^{129}$ Fins i tot la doctrina holandesa ha apuntat, en to crític, que el jutge holandès ha assumit el paper del legislador. ${ }^{130} \mathrm{Si}$ s'accepta aquest darrer punt de vista, ens trobaríem, possiblement, davant d'una usurpació de funcions per part del jutge.

\footnotetext{
125 Vegeu Spier, Shaping the law..., cit., p. 49.

126 Vegeu Bakkes, "Noot", cit., p. 2115-2116.

127 Vegeu Elbert R. de Jong, "Urgenda: rechterlijke risicoregulering alsalternatief voor risicoregulering door de overheid?", Nederlands Tijdschrift voor Burgerlijk Recht, núm. 46, 2015, apartat 6.1 (versió digital).

${ }_{128}$ Vegeu també Elbert R. de Jong, "Case Note, Dutch State Ordered to Cut Carbon Emissions", European Journal of Risk Regulation, núm. 3, 2015, 448-453, p. 448.

129 Vegeu Johannes Saurer / Kai Purnhagen, "Klimawandel vor Gericht - Der Rechtsstreit der Nichtregierungsorganisation 'Urgenda' gegen die Niederlande und seine Bedeutung für Deutschland ", Zeitschrift für Umweltrecht, núm. 27-1, 2016, 16-23, p. 21 ss.

130 Vegeu Bakkes, “Noot”, cit., p. 2116.
} 
Amb tot, l'opinió no és unànime: la doctrina està dividida i també hi ha qui justifica l'actuació judicial. ${ }^{131}$ En efecte, àdhuc en el Dret alemany hi ha qui defensa que una reclamació del tipus Urgenda podria acabar prosperant, i que el Tribunal Constitucional alemany podria acabar reconeixent fins i tot el dret al medi ambient de les generacions futures. ${ }^{132} \mathrm{Al}$ capdavall, el jutge tampoc no pot deixar de pronunciar-se, car no són possibles les sentències non liquet. I si concorren els requisits per a l'aplicació d'una norma jurídica al-legada per les parts, sigui la de responsabilitat civil (com era el cas) o una altra, el jutge l'haurà d'aplicar. En tot cas, també cal discutir si un tribunal de justícia és el millor lloc per a jutjar l'acció d'un govern en un tema tan complex com és el del canvi climàtic. ${ }^{133}$

El que és pitjor, la sentència condemnatòria pot tenir un efecte bumerang. ${ }^{134} \mathrm{En}$ efecte, és possible que a partir d'aquesta sentència els Estats s'ho pensin dues vegades abans de signar acords similars, ja que s'estaran exposant a reclamacions d'aquest tipus. Fins i tot se suggereix que la sentència prepara el camí per a un Estat totalitari, ja que obre la porta perquè qualsevol qüestioni les polítiques de l'Estat. ${ }^{135} \mathrm{Amb}$ tot, es pot donar la volta a l'argument i defensar que, en realitat, el que fa la sentència és donar valor o força a un compromís internacional. Si el que els estats volien era simplement actuar de cares a la galeria i no obligar-se efectivament, el millor és que no concloguin aquests tipus d'acords. En aquest sentit, no es perdia res si es produís l'efecte bumerang esmentat.

En definitiva, és encara massa aviat per jutjar si les reclamacions "a la Urgenda" tindran èxit o no. En el Dret espanyol, la norma de culpa no operaria en un context, com el de la responsabilitat de l'Administració, regit per la responsabilitat objectiva, i des d'aquest punt de vista els hipotètics demandants ho tindrien

\footnotetext{
131 Vegeu Geerten Boogaard, "Urgenda en de rol van de rechter. Over de ondraaglijke leegheid van de trias política ", Ars Aequi, vol. 65, núm. 1, 2016, 26-33, p. 26 ss.

132 Vegeu Marc Zemel, "The rise of rights-based climate litigation and Germany's susceptibility to suit", Fordham Environmental Law Review, núm. 29, 2018, 484-527, p. 525.

${ }^{133} \mathrm{Hi}$ estan contra Lucas Bergkamp / Jaap C. Hanekamp, "Climate Change Litigation against States: The Perils of Court-Made Climate Policies", European Energy and Environmental Law Review, vol. 24, núm. 5, 2015, 102-114, p. 102.

134 Vegeu Lucas Bergkamp, "The Urgenda judgment: a 'victory' for the climate that is likely to backfire", Hunton \& Williams.- Lawyer Insights, September 9, 2015 $<$ http://energypost.eu/urgenda-judgment-victory- climate-likely-backfire> [Darrera consulta, 31 de març de 2018].

135 Vegeu Lucas Bergkamp, "Het Haagse klimaatvonnis", Nederlands Juristenblad, núm. 10, 2015, 2278-2288, p. 2288.
} 
comparativament més fàcil que els seus homòlegs holandesos. Tanmateix, caldria demostrar l'incompliment dels objectius assumits internacionalment. No es pot descartar que els jutges espanyols trobessin alguna base en les consideracions relatives a la causalitat per a argumentar que l'Estat no causa el canvi climàtic. D'altra banda, encara que la reclamació arribés a bon port, podria acabar tractant-se d'una victòria pírrica, ja que de totes maneres és possible que ja sigui massa tard per solucionar el problema del canvi climàtic. En el fons, com tots els juristes saben massa bé, sovint la resposta de l'ordenament jurídic arriba massa tard als problemes que vol resoldre. ${ }^{136}$

Sigui com sigui, mentre restem a l'espera de com acabi un eventual recurs de cassació front del Tribunal Suprem holandès (Hoge Raad), la doble victòria ja obtinguda als dos tribunals inferiors a Holanda suggereix prima facie un futur prometedor. No obstant això, són moltes les incerteses que planen sobre I'horitzó. Està en joc no només una anàlisi tècnica-jurídica sobre els elements de la responsabilitat civil (com la culpa i la causalitat), sinó també un debat polític sobre el paper respectiu del Govern i dels jutges. Que aquest debat es resolgui aviat és convenient no només per a una millor definició del Dret vigent, sinó també per protegir un interès que ens afecta a tots, com és el del medi ambient.

\section{CONCLUSIONS}

La sentència holandesa en el cas Urgenda va suposar el tret de sortida per a una sèrie de reclamacions similars en altres països. El patró o esquema és sempre el mateix: una ONG o un conjunt de ciutadans (o tots ells) demanden l'Estat perquè compleixi amb el compromís internacionalment assumit de reduir les emissions de gasos d'efecte hivernacle o protegir el medi ambient. La majoria d'aquests casos estan encara pendents d'una resolució definitiva, però algunes primeres victòries permeten ser relativament optimistes.

Els casos "a la Urgenda" posen sobre la taula el paper de la responsabilitat civil quan l'Estat deixa de complir els seus deures. Plantegen qüestions d'índole tècnica molt diversa, com són el fonament de la responsabilitat, la causalitat i la

\footnotetext{
136 Vegeu amb més deteniment, sobre aquest problema, Poul Harremöes et al., Late lessons from early warnings: the Precautionary principle 1896-2000, Office for Official Publications of the European Communities. Luxembourg, 2001.
} 
culpa (en els sistemes on aquesta és requisit de la responsabilitat estatal). Suposa també un empoderament de la societat civil contra la passivitat estatal, i subratlla el poder fiscalitzador dels tribunals. Fins ara, l'argument de la separació de poders no ha impedit el triomf de les reclamacions. Amb tot, existeixen nombroses incerteses sobre el futur de les que estan pendents. Especialment, encara cap tribunal no sembla que hagi concedit una indemnització als reclamants, sinó que més aviat es tracta d'intentar obligar a complir els compromisos ja existents. En aquest sentit, ens trobem davant d'un ús instrumental i limitat de la responsabilitat civil. Les victòries judicials donen un evident missatge a la societat en el sentit que el medi ambient importa i que el canvi climàtic s'ha de combatre. Però en el fons es tracta de resolucions que no creen obligacions distintes de les que ja hi havia, i que es poden acabar traduint en una victòria pírrica dels reclamants si no van acompanyades d'alguna cosa més.

\section{BIBLIOGRAFIA}

AHMAD, Nadia B. / UR RASOOL BILAL, Mushtaq, "Monsoons, Hydropower, and Climate Justice in Pakistan 's River Communities", en Randall Abate, Climate Justice: Case Studies in Global and Regional Governance Challenges, West Academic. Washington, 2016, 471-492

ALLEN, M. R. / LORD, R., "The blame game", Nature núm. 432, 2004, 551-552

ARANA GARCÍA, Estanislao, "The Fight Against Climate Change in Spain", European Energy and Environmental Law Review, vol. 20, núm. 5, 2011, 176186

ARIAS MALDONADO, Manuel, "La ideología del clima", Revista de Libros, 10.1.2018

$<$ https://www.revistadelibros.com/articulo_imprimible.php?art=1709\&t=blogs > [Darrera consulta, 16 de desembre de 2018].

ASPINALL, Richard, "Geographical Perspectives on Climate Change", Annals of the Association of American Geographers, vol. 100, núm. 4, 2010, 715-718 $\mathrm{BACH}$, Tracy, "Human Rights in a Climate Changed World: The Impact of COP21, Nationally Determined Contributions, and National Courts", Vermont Law Review, vol. 40, 2016, 561-595 
BÄHR, Cordelia Christiane / BRUNNER, Ursula / CASPER, Kristin / LUSTIG, Sandra H, "KlimaSeniorinnen: lessons from the Swisssenior women's case for future climate litigation", Journal of Human Rights and the Environment, vol. 9, núm. 2, 2018, 194-221

BAKKER, Bob, "Urgenda: International law, Dutch policies and the separation of powers", Medium, 2016, <https://medium.com/@bojbakker/urgendainternational-law-dutch-policies-and-the-separation-of-powers-ee8277735d0a> [Darrera consulta, 31 de març de 2018]

BAKKES, Ch. W., "Noot", AB Rechtspraak Bestuursrecht, núm. 336, 2015, 2112 2116

BECKERMAN, Wilfred / PASEK, Joanna, Justice, Posterity and the Environment, Oxford University Press. Oxford, 2004

BERGKAMP, Lucas, "Het Haagse klimaatvonnis", Nederlands Juristenblad, núm. 10, 2015, 2278-2288

BERGKAMP, Lucas, "The Urgenda judgment: a 'victory' for the climate that is likely to backfire", Hunton \& Williams.- Lawyer Insights, September 9, 2015 <http://energypost.eu/urgenda-judgment-victory- climate-likely-backfire> [Darrera consulta, 31 de març de 2018]

BERGKAMP, Lucas / HANEKAMP, Jaap C., "Climate Change Litigation against States: The Perils of Court-Made Climate Policies", European Energy and Environmental Law Review, vol. 24, núm. 5, 2015, 102-114

BERLINER, L. Mark, "Uncertainty and Climate Change", Statistical Science, vol. 18, núm. 4, 2003, 430-435

BERRY, Thomas, The Great Work, Three Rivers Press. New York, 1999

BESTEFORELDRENES KLIMAAKSJON, "Klimadommen Bor ankes", 2018.01.21 <http://www.besteforeldreaksjonen.no/?p=42073> [Darrera consulta, 31 de març de 2018]

BHARATH, AK / TURNER, RJ, "Impact of climate change on skin cancer", Journal of the Royal Society of Medicine, vol. 102, núm. 1, 2009, 215-218 BOOGAARD, Geerten, "Urgenda en de rol van de rechter. Over de ondraaglijke leegheid van de trias política ", Ars Aequi, vol. 65, núm. 1, 2016, 26-33 BOYLE, Alan, "Human Rights and the Environment: Where Next?", European Journal of International Law, 2012, vol. 23, núm. 3, 613-642 
BRASERO, Roberto, La influencia silenciosa. Cómo el clima ha condicionado la historia, Espasa. Madrid, 2017

BRENNAN, Troyen A. / CARTER, Robert F., "Legal and Scientific Probability of Causation of Cancer and Other Environmental Disease in Individuals", Journal of Health Politics, Policy and Law, vol. 10, núm. 1, 1985, 33-80, p. 33 i ss.

BRUNNÉE, Jutta, "Climate Change, global environmental justice and international environmental law" en Jonas Ebbeson / Phoebe Okowa (eds), Environmental Law and Justice in Context, Cambridge University Press, Cambridge, 2009, 316-331

BUGGE, Hans Christian, "Twelve fundamental challenges in environmental law", en Christina Voigt (ed.), Rule of Law for Nature. New Dimensions and Ideas in Environmental Law, Cambridge University Press, Cambridge, 2003, 3-26, CABANILLAS SÁNCHEZ, Antonio, "La responsabilidad civil por inmisiones y daños al medio ambiente", Anuario de Derecho Civil, vol. 49, núm. 1, 1996, 5-74 CARBONELL, Eudald, Elogio del futuro. Manifiesto por una conciencia crítica de especie, Arpa. Barcelona, 2018

COX, R.H.J., "The Liability of European States for Climate Change", Utrecht Journal of International and European Law, vol. 30, núm. 78, 2014, 125-135

COX, Roger, "A climate change litigation precedent: Urgenda Foundation $v$ The State of the Netherlands", Journal of Energy \& Natural Resources Law, vol. 34, núm. 2, 2016, 143-163

COX, Roger H.J., Revolution Justified, Planet Prosperity Foundation. Maastricht, 2012

DE JONG, Elbert, Voorzorgverplichtingen. Over aansprakelijkheidsrechtelijke normstelling voor onzekere risico's, Proefschrift, Boom juridisch. Den Haag, 2016 DE JONG, Elbert R. / SPIER, Jaap, "Climate Change: A Major Challenge and a Serious Threat to Enterprises", en Dovenschmidt Quaterly, núm . 1, 2013, 36-43. DE JONG, Elbert R., "Urgenda: rechterlijke risicoregulering alsalternatief voor risicoregulering door de overheid?", Nederlands Tijdschrift voor Burgerlijk Recht, núm. $46, \quad 2015 \quad$ (versió digital) <https://www.recht.nl/vakliteratuur/algemeen/artikel/393744/urgendarechterlijke-risicoregulering-als-alternatief-voor-risicoregulering-door-deoverheid/> [Darrera consulta, 16 de desembre de 2017]. 
DE JONG, Elbert R., "Case Note, Dutch State Ordered to Cut Carbon Emissions", European Journal of Risk Regulation, núm. 3, 2015, 448-453.

DE SADELEER, Nicholas, "The Precautionary principle and climate change", en Daniel A. Farber / Marjan Peters (ed.), Climate Change Law. Elgar Encyclopedia of Environmental Law, Elgar. Cheltenham, 2016, 20-31

DE-SHALIT, Avner, The Environment Between Theory and Practice, Oxford University Press. Oxford, 2004

DE VILCHEZ MORAGUES, Paz, "Broadening the scope: The Urgenda case, the Oslo Principles and the role of national courts in advancing environmental protection concerning climate change", Spanish Yearbook of International Law, núm. 20, 2016, 71-92

EGEA FERNÁNDEZ, Joan, "Condiciones medioambientales y derechos fundamentales. Inmisiones perjudiciales que obligan a abandonar el domicilio (a propósito de la Sentencia del TEDH de 9 de diciembre de 1994)", Derecho Privado y Constitución, núm. 9, 1996, p. 323-364

EXPERT GROUP ON CLIMATE OBLIGATIONS OF ENTERPRISES, Principles on Climate Obligations of Enterprises, Eleven International Publishing. The Hague, 2018

FOSTER, Sheila R. / GALIZZI, Paolo, "Human rights and climate change: building synergies for a common future", en Daniel A. Farber / Marjan Peters (ed.), Climate Change Law. Elgar Encyclopedia of Environmental Law, Elgar. Cheltenham, 2016, 43-63

FRENCH, Duncan / PONTIN, Benjamin, "The science of climate change: a legal perspective on the IPCC", en Daniel A. Farber / Marjan Peters (ed.), Climate Change Law. Elgar Encyclopedia of Environmental Law, Elgar. Cheltenham, 2016, 9-19

GARDINER, Stephen M. / CANEY, Simon / JAMIESON, Dale / SHUE, Henry (eds.), Climate Ethics. Essential Readings, Oxford University Press. New York, 2010

GOSSERIES, Axel / MEYER, Lukas H., "Introduction — Intergenerational Justice and Its Challenges", en Axel Gosseries / Lukas H. Meyer, Intergenerational justice, Oxford University Press. Oxford, 2010, 1-21 
GREENPEACE NORWAY, "Tingretten frifinner staten", 2018.04.01 $<$ http://www.greenpeace.org/norway/no/Tingretten-frifinner-staten/> [Darrera consulta, 31 de març de 2018]

HALL, Matthew, "State Responsibility for the ADverse Impacts of Climate Change on Individuals: Assessing the Potential for an Interdisciplinary Approach", en Stephen Farrall / Tawhida Ahmed / Duncan French (eds.), Criminological and Legal Consequences of Climate Change, Hart. Oxford and Portland Oregon, 2012, 215-240

HARREMÖES, Poul, et al., Late lessons from early warnings: the Precautionary principle 1896-2000, Office for Official Publications of the European Communities. Luxembourg, 2001

HAYWARD, Tim, "Human Rights Versus Emissions Rights: Climate Justice and the Equitable Distribution of Ecological Space", Ethics \& International Affairs, 2007, vol. 21, núm. 4, 431-450

KING, David / SCHRAG, Daniel / DADI, Zhou / YE, Qi / GHOSH, Arunabha, $\begin{array}{llll}\text { Climate Change. A Risk Assessment, } 2015 & \end{array}$ $<$ http://www.csap.cam.ac.uk/projects/climate-change-risk-assessment/> [Darrera consulta, 31 de març de 2018] KLEIN, Naomi, This Changes Everything, Penguin. London, 2014.

LEOPOLD, Aldo, Una ética de la tierra, Catarata. Madrid, 2017 (2ª . edición). MASLIN, Mark, Climate Change. A Very Short Introduction, Oxford University Press. Oxford, 2014 (3 ${ }^{\text {rd }}$ edition)

OLABE EGAÑA, Antxon, Crisis climática-ambiental. La hora de la responsabilidad, Galaxia Gutenberg. Barcelona, 2016

PANTALEÓN PRIETO, Fernando, "Los anteojos del civilista: hacia una revisión del régimen de la responsabilidad patrimonial de las Administraciones Públicas", Documentación administrativa, núm. 237-238, 1994, 239-254, p. 239.

PÖTTKER, Erik, Klimahaftungsrecht. Die Haftung für die Emission von Treibhausgasen in Deutschland und den Vereinigten Staaten von Amerika, Mohr Siebeck. Tübingen, 2014

ROBERTS, J. Timmons / PARKS, Bradley C., "Ecologically Unequal Exchange, Ecological Debt, and Climate Justice. The History and Implications of Three 
Related Ideas for a New Social Movement", International Journal of Comparative Sociology, 2009, vol. 50, núm. 3-4, 385-409

ROBINSON, Mary, "Foreword", en Stephen Humphreys (ed.), Human Rights and Climate Change, Cambrigde University Press. Cambridge, 2010, xvii-xx

RODRÍGUEZ GARCÍA, Noel, "Responsabilidad del Estado y cambio climático: el caso Urgenda c. Países Bajos", Revista Catalana de Dret Ambiental, vol. 7, núm. 2, 2016, 1-38

RUDA GONZÁlEZ, Albert, El daño ecológico puro, Thomson Aranzadi. Cizur menor, 2007

RUDA GONZÁLEZ, Albert, "From Salamander's Wool to Lethal Dust: Asbestos Liability Under Spanish Law in Light of Heneghan", European Review of Private Law, 2017, vol. 25, núm. 6, 1117-1133

SACHS, Jeffrey D., La era del desarrollo sostenible, Ediciones Deusto. Barcelona, 2015

SAURER, Johannes / PURNHAGEN, Kai, "Klimawandel vor Gericht - Der Rechtsstreit der Nichtregierungsorganisation 'Urgenda' gegen die Niederlande und seine Bedeutung für Deutschland ", Zeitschrift für Umweltrecht, núm. 27-1, 2016, 16-23

SELBY, Jan / DAHI, Omar S. / FRÖHLICH, Christiane / HULMEE, Mike, "Climate change and the Syrian civil war revisited", Political Geography, 2017, vol. 60, 232-244

SPIER, Jaap, "Injunctive relief", en Jaap Spier / Ulrich Magnus (eds.), Climate change remedies: injunctive relief and criminal law responses, Eleven International. The Hague, 2014, 1-120

SPIER, Jaap, Shaping the law for global crises: thoughts about the role the law could play to come to grips with the major challenges of our time, Eleven International Publishing. The Hague, 2012

VERSCHUUREN, Jonathan, "Urgenda Climate Change Judgment Survives Appeal in the Netherlands", IUCN, 24 Oct 2018, <https://www.iucn.org/news/world-commission-environmentallaw/201810/urgenda-climate-change-judgment-survives-appeal-netherlands> [Darrera consulta, 16 de desembre de 2018]. 
WELLS, Alan, "Climate Change: The Final Countdown", European Environmental Law Review, núm. 3, 2007, 62-65

WORLAND, Justin, "How Climate Change Could Make the Migrant Crisis Worse", Time, $2017<$ <ttp://time.com/5076003/climate-change-migration-trump/> [Darrera consulta: 16 de desembre de 2018]

ZAHAR, Alexander, "Mediated versus Cumulative Environmental Damage and the International Law Association's Legal Principles on Climate Change", Climate Law, vol. 4, núm. 3-4, 2014, 217-233

ZEMEL, Marc, "The rise of rights-based climate litigation and Germany's susceptibility to suit", Fordham Environmental Law Review, núm. 29, 2018, 484527

ZHANG, Xiao-Bing / HENNLOCK, Magnus, "The benefits of international cooperation underclimate uncertainty: a dynamic game analysis", Environment and Development Economics, núm. 23, 2018, 452-477 